\title{
JOB ACCESSIBILITY AND JOB-EDUCATION MISMATCH IN THE METROPOLITAN AREA OF BARCELONA
}

This paper analyses the effect of job accessibility on job-education mismatch in the metropolitan area of Barcelona with regard to both public and private transport. Transit accessibility is defined in terms of the spatial distribution of employment relative to travel time by public transport, whereas accessibility by private transport is approximated by car availability. The results obtained from a joint model for car ownership, employment selectivity and mismatch confirm that car availability matters for job-education mismatch. Moreover, public transport connectivity to job locations favours the matching between schooling and occupation in the urban labour market.

Keywords: job-education mismatch, job accessibility, public transport, car availability, Barcelona JEL Classifications: J61, J21, O18, P25, R41

\section{1) Introduction}

The correct allocation of individuals' human capital in the economy is a crucial element for economic growth at both national and local levels. However, a substantial number of individuals hold jobs that are not well matched with their qualifications. The so-called job-education mismatch, especially when it takes the form of over-education (i.e. a surplus of schooling relative to the job), represents a policy-relevant issue in several European countries, especially in southern countries such as Spain (Flisi et al., 2014). Since the early 2000s, several researchers have highlighted the role of spatial factors in explaining job-education mismatch which could be partly owed to the spatial disconnection between individual's residential locations and suitable job opportunities. The lack of accessibility to adequate jobs could drive individuals to accept occupations that are well 
below their qualifications. This is because, on the one hand, the spatial constraints on reaching potential employment centres might reduce job search efficiency. ${ }^{1}$ On the other hand, when commuting costs are too high people could end up accepting jobs for which they are overqualified. The existing literature (see Section 2) suggests that spatial flexibility ${ }^{2}$ favours job matching, especially in terms of physical accessibility to jobs - i.e. when it is defined in terms of commuting time/distance or private car availability.

This paper aims to provide new insights about the relationship between job accessibility and mismatch in an urban labour market. Analysing this topic in metropolitan areas is especially relevant because urban labour markets are characterised by higher competition between highly educated workers. Moreover, the waste of human capital because of mismatch is more pronounced in cities because of the higher rate of return to schooling driven by agglomeration effects (Combes and Gobillon, 2015). Hence, we offer a novel perspective on the relationship between spatial connectivity to potential employment and job-education mismatch by focusing on the metropolitan area of Barcelona. To the best of our knowledge, ours is the first work to adopt an urban perspective to analyse this issue, since previous studies only provide evidence at the national level. The urbanbased analysis also makes it necessary to extend the concept of job accessibility by explicitly taking into account the role played by public transport facilities. In a metropolitan area, commuting costs clearly depend on the transport modes available. In a context of decentralised employment and residences (as in the case of Barcelona), private transport may have advantages over public transport regarding flexibility and time costs. For those living far from job centres, cars are quicker and are sometimes the only available alternative for connecting places of residence and job alternatives. Therefore, since workers who are limited to public transport will usually face higher time costs in terms of reaching the same job opportunities as car users, alternative modes of

\footnotetext{
${ }^{1}$ This is consistent with the theoretical models that have been developed in relation to the Spatial Mismatch Hypothesis (see Gobillon et al., 2007 for an overview).

${ }^{2}$ Note that spatial accessibility broadly refers to both the willingness to migrate in search of better job opportunities and the physical accessibility to potential jobs more suited the applicants' educational qualifications.
} 
transport must be taken into account in explaining spatial differences in urban labour market outcomes (see Gautier and Zenou, 2010, for detailed theoretical arguments). Previous studies focused on job-education mismatch considered the relevance of private car availability and broad measures of accessibility, without making the distinction between job connectivity by private and public transport. ${ }^{3}$ Therefore, this paper also adds to the international literature by explicitly considering the role of public transport accessibility in job-education mismatch in the urban labour market.

The empirical analysis is based on the joint modelling of car ownership and job-education mismatch that enables transit connectivity to be a determinant of car availability as well. In this way we account for the existing substitutive relationship between public and private transport and thus obtain the direct effect of public transport accessibility and car availability on mismatch. Moreover, we also controlled for employment selectivity (as usually done in the literature), ${ }^{4}$ since the mismatch variable is observed only for those who are regularly employed, and we also allowed for correlation between the unobserved determinants of vehicle ownership and labour market outcomes (while previous papers on mismatch treat car availability as an exogenous variable).

The estimation of the joint system of equations was carried out separately by gender, in order to account for different labour market attachment and employment selectivity, as well as for the fact that women are less likely to have access to the family car for commuting (and thus are more dependent on public transport). Public transport accessibility is initially treated as an exogenous variable. However, we recognised that endogenous residential sorting of individuals could create a spurious relationship between transit accessibility and labour market outcomes. We therefore

\footnotetext{
${ }^{3}$ On the contrary, the role of public transport has been considered in several papers that analyse the impact of job accessibility on employment outcomes under the hypothesis of spatial mismatch. See, for instance, Sanchez (1999), Kabawata (2003), Holzer et al. (2003), Matas et al. (2010) and Korsu and Wenglenski (2010).

${ }^{4}$ See Büchel and van Ham (2003), Jauhiainen (2011), Ramos and Sanromà (2013), Devillanova (2013), Iammarino and Martinelli (2014) and Croce and Ghignoni (2015), among others.
} 
performed several robustness checks ${ }^{5}$ aimed at ruling out the possibility that the relationship between job accessibility by public transport and mismatch is (entirely) driven by residential sorting. The rest of the paper is organised as follows. In Section 2 we briefly review the existing literature, highlighting the relevance of spatial connectivity to job-education mismatch. In Section 3 we present the data and some descriptive evidence. Section 4 describes the empirical strategy, Section 5 contains the empirical results (the corresponding robustness checks are reported in the Appendix) and Section 7 concludes.

\section{2) Related Literature}

A substantial number of empirical studies have analysed the relevance of spatial accessibility to jobs from the individual's place of residence on labour market performance. Much of this research is based on the so-called Spatial Mismatch Hypothesis (Kain, 1968). This literature is mostly focused on labour market performance of ethnic minorities in US cities (for a review, see Ihlanfeldt and Sjoquist, 1998, Ihlanfeldt, 2006, Zenou, 2008 and Gobillon and Selod, 2014). However, an increasing number of empirical studies support the negative effect of the spatial disconnection between residential and job locations on labour market outcomes for European cities ${ }^{6}$ that have experienced a job decentralisation process (see Patacchini and Zenou, 2005 for England; Åslund et al., 2010 and Norman et al., 2012 for Swedish cities; Matas et al., 2010 for two Spanish cities and Korsu and Wenglenski, 2010 for Paris-Île-de France). Nowadays the existing link between connectivity to potential employment centres from residential location and labour market outcomes such as employment and earnings is well-established.

\footnotetext{
5 Additional sensitivity analyses also consider the robustness of the results to the inclusion of a measure of private transport accessibility that is based on the spatial distribution of jobs relative to commuting time from residential place by private vehicles, as well as to the fact that car availability is defined at the household level.

${ }^{6}$ Nonetheless, the results for European cities are less conclusive than for US cities. For instance, Gobillon and Selod (2008) reported only slight evidence of a negative effect of job accessibility on the probability of finding a job in Paris. Moreover, Dujardin et al. (2008) found that distance to jobs is not significant in explaining employment probability in the area of Brussels.
} 
However, in the last decade a new and related field of research emerged, which is not explicitly restricted to disadvantaged workers. This line of research emphasises the importance of spatial flexibility for the incidence and the extent of job-education mismatch (i.e. when the individual's educational qualifications do not correspond to the requirements of the workplace). ${ }^{7}$ Indeed, overeducation, among other things, can be the result of a spatially constrained job search, which in turn depends on the combination of the spatial distribution of job opportunities and the individual's spatial flexibility. In the seminal paper by Büchel and van Ham (2003), the concept of spatial flexibility is defined by means of a car availability indicator and the average commuting time to the nearest agglomeration with a private car. Both variables are likely to approximate the spatial disconnection to potential workplaces. Drawing on German data, the authors found that car availability is significantly associated with a lower probability of being over-educated, whereas the opposite is true for an increase in travel time to the nearest agglomeration. This evidence is consistent with the idea that increasing accessibility to potential employment centres may reduce the risk of being mismatched in the labour market. Similar evidence has been reported by Büchel and Battu (2003), who also used German data and focused on the effect of commuting distance (among other things). They reported that higher commuting distance, which captures spatial constraints, is conditionally associated with lower probability of over-education.

Hensen et al. (2009) analysed the relevance of geographic mobility for explaining the risk of mismatch among Dutch university graduates, considering as mobility the (straight-line) distance between the municipality where graduates studied and the one where they worked at the time of the survey. The authors focused on the likelihood of having a job below the acquired education level (vertical mismatch or over-education) or outside the field of study (horizontal mismatch), as well as

\footnotetext{
${ }^{7}$ Most of the papers belonging to the above-mentioned line of research are more directly focused on the case of over-education (i.e. the surplus of schooling in individual's occupation), which seems to be the most detrimental case of mismatch. In fact, the extensive literature on this topic highlights that being over-educated represents a situation of underemployment and generates a waste of human capital, which is associated with lower productivity, lower remuneration (in relation to equally-educated but well-matched workers), and increased risk of quitting work and job dissatisfaction (see McGuinnes, 2006 and Leuven and Oosterbeek, 2011 for comprehensive reviews).
} 
other job quality outcomes (i.e. having a part-time or fixed-term contract or a low-paid job). They found that more mobile graduates are less exposed to the risk of over-education but more exposed to horizontal mismatch than their less mobile counterparts. The paper by Jauhiainen (2011) is based on Finnish data and uses two set of variables to capture spatial flexibility: first, between regions (long-distance) and between municipality (short-distance) mobility and, second, car availability. The author carried out separate estimations by gender and found that long-distance mobility negatively affects the probability of being over-educated, whereas the opposite is true for short-term mobility among males. Surprisingly, he also found that having a car is not statistically significant in the over-education equation. Ramos and Sanromà (2013) examined the relevance of spatial factors in explaining the incidence of over-education in the Spanish labour market by using two crosssections of data (1990-91 and 2006). They considered two variables that captured job accessibility at the individual and regional levels, namely private car availability and the number of road kilometres per car respectively. The results from their analysis suggest that car ownership is negatively associated with surplus schooling and the regional quality of transport infrastructures has a negative impact on mismatch only in the 1990-91 database. Other papers studied the relationship between spatial flexibility and over-education for the Italian case. Devillanova (2013) and Croce and Ghignoni (2015) captured individuals' spatial flexibility by using information about commuting time to work and migration decisions and both considered the endogeneity of migration, ${ }^{8}$ as it represents a choice variable that may be related to unobservable determinants of mismatch. Both papers report that the increase in commuting time is associated with better quality in terms of the match between education and occupation, albeit migration seems to be beneficial for job-education mismatch only among university graduates (according to the results reported in Croce and Ghignoni, 2015).

\footnotetext{
${ }^{8}$ It is worth noting that Iammarino and Martinelli (2014) focused on the effect of inter-regional migration in explaining job-education mismatch among Italian university graduates and also controlled for endogenous migration decisions.
} 
The general lesson that can be derived from the existing literature is that spatial flexibility matters for improving the match between education and occupation, especially when defined in terms of physical accessibility to potential job opportunities (i.e. car availability of commuting distance/time). However, to the best of our knowledge, none of the existing papers have specifically focused on urban areas and explicitly examined the role played by public transport job accessibility in explaining job-education mismatch (as well as its interrelationship with private transport availability). As noted above, these two elements are especially relevant in urban areas, since commuting by car is not always feasible, and the availability of an efficient public transport network could reduce job-search costs. Therefore, we try to fill this gap in the literature relating to spatial flexibility and job quality by providing evidence regarding the importance of public transport connectivity to potential job locations in reducing job-education mismatch in an urban labour market.

\section{3) Data and Descriptive Statistics}

\section{1) Data Description}

This study draws on data from the 2001 Spanish Micro-Census, which covers 5\% of the Population Census. The main advantages of this dataset are its large sample size and the level of spatial disaggregation of the information, which enables the definition of territorial variables using very small spatial units (census tract level). Therefore, the 2001 Micro-Census is the only source of information $^{9}$ that can be used to locate jobs on a municipal level and hence construct a precise measure of job accessibility. The database also provides information on several individual characteristics (among others: age, gender, nationality, marital status, level of education, field of

\footnotetext{
${ }^{9}$ Note that even if the 2001 database is somewhat dated, it is the latest (census population) database that enables precise and reliable estimation of the spatial location of jobs. The novel data from the new Spanish Micro-Census of 2011 do not represent a valid alternative for identifying the number of jobs at the municipality level, since census-tract identifiers are not provided.
} 
tertiary education, labour market status and occupation) and on a large number of household characteristics (household composition, number of children, number of working adults, number of cars and housing-related information). We retained observations on the metropolitan area of Barcelona, which is the urban area of interest in this paper. Since our final aim is to analyse the impact of job connectivity on the extent of job-education mismatch, we selected individuals aged between 16 and 64 who are not permanently retired and are not disabled. We excluded individuals enrolled in education (10\% of the sample). We also dropped individuals who are either selfemployed or employers, because of the intrinsic difficulty of defining job-education mismatch for these groups of workers (12.2\%), as well as nine individuals whose occupation had fewer than 20 observations (as required to construct job-education mismatch, see below). Finally, we also excluded the small number of individuals living in households where there are multiple families (about 1\%), since the number of cars is defined at the household level whereas the number of adults (and family composition in general) is defined at the family level. We ended up with a sample comprising 93,038 observations on the Barcelona metropolitan area (44,077 males and 48,961 females).

\section{2) Variables definition}

The main labour market outcome that we analyse in this paper consists of job-education mismatch, which represents a meaningful measure of job quality. By mismatch we mean the extent to which the educational qualification of workers corresponds to what is required in the workplace. There are several alternative ways of defining job-education mismatch and the discussion about which method is better than the others is still open (see Hartog, 2000, McGuinness, 2006, Verhaest and Omey, 2006 and Leuven and Oosterbeek, 2011 for more details). ${ }^{10}$ Usually, as is the case with

\footnotetext{
10 There are three general ways to define job-education mismatch and, consequently, to classify a given worker as over-educated: the Job Analyst approach, (direct and indirect) Self-Assessed classification and the Realised Matches method. In the first definition, required schooling is obtained from information contained in occupational classifications, which is not easily available and is subject
} 
the present study, the ultimate choice mostly depends on data availability. Since the Census database does not contain any direct information about qualification requirements in the workplace, we use the Method of Realised Matches to define job-education mismatch (as done by Jauhiainen, 2011, Ramos and Sanromà, 2013 and Rubb, 2014, among others). Therefore, we define jobeducation mismatch as the difference between an individual's years of schooling ${ }^{11}$ and average schooling in the corresponding occupation (two-digit national classification). On the basis of this continuous mismatch variable, an individual is considered to be over-educated (the most detrimental case of mismatch) if he/she has more schooling than the average for his/her occupation plus one standard deviation point.

The key right-hand side variables for this study are those capturing spatial connectivity from the neighbourhood of residence to the workplace by public transport services and private vehicles. For the former, we considered a measure that captures employment potential for each zone of residence and commuting time by public transport. According to Rogers (1997), a measure of market potential should take into account the spatial distribution of jobs and the distance or cost involved in reaching them. The employment potential fulfils both requirements. According to the literature, the most suitable variable for capturing employment potential should be the number of vacancies but, unfortunately, we did not have information on job vacancies. Therefore, the total number of jobs located in each zone has been taken as a proxy for vacancies. The implicit assumption is that zones with a higher number of jobs will also generate a higher number of

\footnotetext{
to time inconsistencies because of changes in complexity within occupations. The second definition relies on direct questions about whether attained education qualifications are adequate or excessive in the current job. Self-assessed measures of mismatch are often unavailable and are subject to misclassification errors because of their subjectivity, as well as to the influence of expectations and adaptation relative to the current working situation. The last method, which is the one employed in this paper, has been criticised because it implicitly assumes that mismatch only results from search and information friction and not from institutional constraints. Moreover, it neglects variations in schooling requirements within occupations and the choice of one standard deviation point to classify the over-educated is considered to be somewhat arbitrary.

11 Years of schooling have been imputed from completed education level with the following conversion rule: 0 years for illiterate, 2 for uncompleted primary education, 6 for completed primary education, 8 for lower secondary education, 12 for upper secondary education, 12 for vocational training, 14 for advanced vocational training, 15 for short-term university degree, 17 for university degree and 20 for doctoral studies. The same variable has been used to compute job-education mismatch with the realised matches approach.
} 
vacancies (Rogers, 1997). More specifically, job accessibility by public transport has been defined

as:

$p t a_{k}=\sum_{j} \frac{e m p l_{j}}{t_{k j}}$

where $\mathrm{empl}_{j}$ is the number of jobs located in zone $j, t_{k j}$ is the travel time on public transport between $k$ and $j, k$ is the individual's zone of residence and $j$ is the destination zone. Therefore, job accessibility for an individual resident in zone $k$ depends on the sum of employment opportunities in each destination zone $j$, inversely weighted public transport travel time between $k$ and $j$. Concerning residential areas, transport zones represent the geographic unit of analysis. These are a subdivision of municipalities used to calculate travel time matrixes. Destination zones are defined at the municipal level, as this is the smallest spatial unit for which the number of jobs is available. However, in order to improve the accuracy of the accessibility measure within the city of Barcelona, jobs are calculated at the district level. The computed index uses job locations from the 2001 Population Census. Commuting times are based on real network data and are obtained from the official travel time matrix. For intra-zonal trips, a commuting time was assigned according to the implicit radius corresponding to the surface of each municipality or district. Overall, this variable $^{12}$ provides a measure of the extent to which the lack of public transport can diminish potential job opportunities.

Regarding job connectivity by private transport, we tried to specify another accessibility variable defined in the same fashion as public transport accessibility but also defined in terms of commuting time by private car. However, preliminary estimation revealed that the relevant way to approximate job accessibility by private transport in the metropolitan area of Barcelona was not

\footnotetext{
12 As suggested by Bunel and Tovar (2013), the use of alternative measures of job accessibility might lead to different results. Therefore, we checked the sensitivity of our results obtained under different definitions of job accessibility by public tran sport. First, in order to take into account the limited number of job opportunities available in the area, we computed an alternative index that uses occupied jobs and active workers. Second, we tested an exponential decay function by weighting public transport time by parameters ranging between 0.5 and 2.0. In all cases the results appeared fairly robust with respect to the original ones. Therefore, we retained the results obtained with the simplest non-weighted measure of employment.
} 
commuting time by car to reach potential jobs but rather the car availability in the household (the Appendix contains more details on this point). Therefore, we retained the number of cars in the household to capture spatial connectivity by private transport. The Spanish Census provides information about the number of available cars in the family, which is collected into four original categories: no cars, one car, two cars and three or more cars. We then grouped the last two categories, given the low number of observations with three cars or more in the household (5\% of the selected sample).

\section{3) Descriptive statistics}

In 2001, the metropolitan area of Barcelona measured 3,263 square $\mathrm{km}$ and had 4.4 million inhabitants distributed among 164 municipalities, which implies an average density of 1,380 inhabitants per $\mathrm{km}^{2}$. The central city, with a relatively small area of around $100 \mathrm{~km}^{2}$, comprises somewhat more than one-third of the whole population, with a population density of 15,150 inhabitants per $\mathrm{km}^{2}$. The area can be considered polycentric, composed of a central business district (the core of the area, made up of Barcelona city and eight surrounding municipalities), where 57\% of the total employment is concentrated, and a significant number of secondary job centres. Job density shows substantial differences between municipalities (as can be appreciated in Figure 1), with an average of 476 jobs per $\mathrm{km}^{2}$ in the metropolitan area and around 7900 jobs per $\mathrm{km}^{2}$ in the city of Barcelona. In recent decades, a process of employment and residential decentralisation has taken place, as a result of which the central city has lost both population and jobs in comparison with the metropolitan area as a whole. It is interesting to note that the process of population suburbanisation has been lower for high earners, whereas employment decentralisation has been lower for jobs filled by those with post-compulsory education levels.

[FIGURE 1 ABOUT HERE] 
Across the metropolitan area of Barcelona, the index of public transport accessibility ranges from 10 for the zone with the lowest accessibility to 61,427 for the zone with the highest, with an average of 32,087 . The spatial distribution of public transport job accessibility is depicted in Figure 2, which shows that job opportunities can be more easily reached by public transport in the capital city, along the coast to the south of Barcelona and in the west of its metropolitan area. The public transport system network has been designed to improve accessibility and mitigate the negative effect of employment concentration in specific segments of the metropolitan area.

[FIGURE 2 ABOUT HERE]

Since public and private transport are clearly alternative ways of reaching job opportunities, we expect families residing in areas served by better public transport infrastructure to be, on average, less dependent on private transport. Offering a first impression of this relationship, Figure 3 shows a scatter plot of the (census tract average) number of cars ${ }^{13}$ with respect to job accessibility by transit which highlights a negative and significant relationship between these two variables.

\section{[FIGURE 3 ABOUT HERE]}

The same relationship can be also appreciated in Table 1, which indicates that the higher the quintile of job accessibility, the lower the proportion of families with more than one car (and the higher incidence of having no car in the household). The same table reports row differentials in unconditional employment probabilities by public transport accessibility and car availability respectively (separately computed for males and females). The number of employed individuals is significantly higher in the male subsample. This is because a significant proportion of women declare that they are involved in housework (30\%), whereas the incidence of 'formal' unemployment (i.e. actively looking for a job) is similar for both genders. The increase in car availability is associated with higher chances of being employed for both genders. Conversely, the statistical association between public transport accessibility and employment is less clear for

\footnotetext{
${ }^{13}$ Note that the measure of public transport accessibility has been divided by 10,000 for the purpose of descriptive statistics and the subsequent econometric analysis.
} 
females and even appears to be negative for males. In addition, both forms of spatial connectivity to employment locations seem to be negatively associated with job quality, since the extent of jobeducation mismatch (i.e. the difference between years of schooling and the corresponding average for the occupation), as well as the proportion of individuals who are classified as over-educated ${ }^{14}$ (i.e. mismatch greater than the standard deviation of schooling within each occupation), increases with job accessibility by public transport and with car availability as well.

\section{[TABLE 1 ABOUT HERE]}

Nevertheless, the unconditional relationship between public transport accessibility to the workplace, car ownership, employment and job-education mismatch that we observed in the raw data is likely to be confounded by other individual and family/household characteristics that co-vary with these variables. Educational attainments represent the clearest example: in fact, more educated individuals might reside in neighbourhoods endowed with a better public transport network and, in principle, they are more likely to be able to afford a (more) car(s), but at the same time they face a higher risk of being more skilled than is required in the workplace. Also, the bivariate relationship between public transport accessibility and car availability could be affected by confounding factors such as family structure, family wealth and neighbourhood effects. Therefore, in what follows we present the empirical strategy that we adopted to rule out the effect of covariates from the (complex) relationship between job accessibility by public transport and car ownership, with the aim of obtaining a direct ceteris paribus effect of our variable(s) of interest in a multivariate framework. The explanatory variables have been selected according to standard literature ${ }^{15}$ related to each of the three endogenous variables that we want to explain (i.e. car ownership, employment and job-

\footnotetext{
${ }^{14}$ The incidence of over-education that we obtain from our sample (about $16 \%$ and similar for males and females) is somewhat lower than that reported in other studies on the Spanish economy (see Ramos and Sanromà, 2013 for an overview), probably because our data refer to the metropolitan area of Barcelona where the demand for high-skilled work is substantially higher than in other parts of Spanish territory.

${ }^{15}$ We mostly followed Büchel and van Ham (2003), Hensen et al. (2009), Jauhiainen (2011), Matas et al. (2010), Ramos and Sanromà (2013), Devillanova (2013) and Croce and Ghignoni, (2015), among others. The labels of all the control variables included in the empirical analysis are self-explanatory and are not discussed in detail for reasons of brevity.
} 
education mismatch) and are listed (together with basic descriptive statistics by gender) in Table A1 in the Appendix. Tables A2a and A2b contain the corresponding correlation coefficients, separately computed for males and females.

\section{4) Econometric Model}

In this section, we present the empirical strategy that we adopted to analyse the effect of public transport accessibility and car ownership on job-education mismatch. We explicitly consider that car ownership $\left(\right.$ carsi $\left._{i}\right)$ is a choice variable that depends on observable and unobservable characteristics, whereby some of the unobservable determinants of car ownership are likely to affect labour market outcomes as well. Moreover, we allow public transport accessibility (pta ) to affect the number of cars in the household, in order to take into account the interrelations and the potential substitutability between public and private transport. Additionally, given that job-education mismatch $\left(\right.$ mismatch $\left._{i}\right)$ can be observed only among employed individuals (i.e. empli $=1$ ), to estimate consistently the impact of transit accessibility and car ownership on mismatch we correct for self-selection in employment. Finally, we allow both public transport accessibility and car availability to affect the likelihood of being employed as well. Therefore, the empirical analysis is based on a recursive system of equations that takes into account all the above-mentioned issues. Specifically, we simultaneously estimate the following three-equation system by means of Limited Information Maximum Likelihood: ${ }^{16}$

$$
\begin{aligned}
& \operatorname{mismatch}_{i}=\alpha+\beta^{\prime} X_{i}+\gamma p t a_{k}+\sum_{l=1}^{L} \delta_{l} I\left(\operatorname{cars}_{i}=l\right)+\varepsilon_{i} \text { if empl } l_{i}=1 \\
& \operatorname{Prob}\left(\operatorname{empl}_{i}=1\right)=\operatorname{Prob}\left(\operatorname{empl} l_{i}^{*}>0\right)
\end{aligned}
$$

\footnotetext{
16 The estimations are carried out with the STATA cmp routine, developed by Roodman (2011). Given that the three equations contain public transport accessibility in the list of regressors, which is defined at the census-tract level, we cluster the standard errors at the census-tract level in order to account for the potential correlation between the error terms of individuals who reside in the same (census-based) area, which also corrects for heteroscedasticity of the error term(s).
} 


$$
\begin{aligned}
& \operatorname{empl}_{i}^{*}=\pi+\omega^{\prime} X_{i}+\psi^{\prime} Z_{i}+\lambda p t a_{k}+\sum_{l=1}^{L} \theta_{l} I\left(\operatorname{cars}_{i}=l\right)+u_{i} \\
& \operatorname{Prob}\left(\operatorname{cars}_{i}=l\right)=\operatorname{Prob}\left(\mu_{l-1}<\operatorname{cars}_{i}^{*} \leq \mu_{l}\right) \\
& \operatorname{cars}_{i}^{*}=\varphi^{\prime} X_{i}+\eta^{\prime} W_{i}+\tau p t a_{k}+v_{i} \\
& \left(\varepsilon_{i}, u_{i}, v_{i}\right) \sim N(0, \Omega), \quad \Omega=\left(\begin{array}{ccc}
\sigma_{\varepsilon}^{2} & \sigma_{\varepsilon u} & \sigma_{\varepsilon v} \\
& 1 & \sigma_{u v} \\
& & 1
\end{array}\right)
\end{aligned}
$$

Equation (1) relates job-education mismatch with job accessibility by public transport, controlling for a vector of exogenous controls $\left(X_{i}\right)$ and dummies for the number of available cars (taking zero cars as reference category). Note that we preferred to use as the dependent variable the continuous 'job-education mismatch' (i.e. the difference between an individual's years of schooling and the average for his/her corresponding occupation) rather than the categorical variable 'overeducation', since this latter option would cause a loss of information. Even so, in what follows we evaluate the impact of our variables of interest in terms of the 'amount' of over-education (as explained in the following section).

To account for employment selectivity, we specify the employment-selection equation (Equations 2a and 2b), which explains the probability of being employed (using a Probit specification) as a function of individual and family characteristics, plus public job accessibility and car availability. This approach corresponds to the ML formulation of the Heckman Selection Model, extended to include the presence of an endogenous regressor in the selection equation and in the final outcome as well.

Finally, the car ownership equation is modelled with an Ordered Probit specification ${ }^{17}$ (Equations 3a and 3b), which is more suitable for use with a dependent variable (i.e. number of cars in the family) that is defined over three discrete values $(0,1$ and 2 or more cars). This car equation

\footnotetext{
${ }^{17}$ Similar results are obtained with a linear specification of the car equation, albeit somewhat more imprecise, which indicates that functional form assumptions do not play a fundamental role (the full estimates are available upon request).
} 
includes as controls a set of individual and family covariates, housing and local variables and, more importantly, public transport accessibility. Note also that the error terms of these three equations are allowed to be correlated (as expressed by Equation (4)) and are assumed to follow a multivariate normal distribution. This means that we enable the unobservable determinants of the number of cars in the family, employment and mismatch to share common elements that would bias the coefficient of interest if the three equations were estimated separately. ${ }^{18}$

The specified system of equations follows a recursive structure, in the sense that the outcome of Equation (3b) is a determinant of Equations (1) and (2b), Equation (2a) identifies the subsample used to estimate Equation (1), but the final outcome of Equation (1) does not enter the list of righthand side variables of Equation (3). This means that the potential simultaneous relationship between the three outcomes of interest is not directly modelled, but is instead captured by the implied correlation between the error terms. Given the non-linearity of Equations (2) and (3), the recursive system would be identified even if the variables included in the three equations were exactly the same. We consider the same set of exogenous covariates $(X)$ for the three equations. These contain socio-demographic information (age, place of birth and marital status), educational attainment (completed education and field of tertiary education, if applicable) and local variables (an indicator for residing in the capital city and local unemployment rate, ${ }^{19}$ which help in picking up local labour market effect and residential segregation). However, in order to avoid weak identification, we introduce several exclusion restrictions to the employment $(Z)$ and car ownership $(W)$ equations, i.e. variables that are strong determinants of employment and car availability but can be assumed to be unrelated to job-education mismatch. The finding of valid exclusion restrictions with observational

\footnotetext{
${ }^{18}$ In Section 5 we also provide estimates of the correlation between error terms and their statistical significance. Failure to reject the null hypothesis of zero (pairwise) correlation means that the separate estimation of the underlying equations would produce biased parameters. Notice also that the estimates are correct under the normality assumption, which is not trivial; however, given the large sample size, this distributional assumption can be assumed to be reasonably valid.

${ }^{19}$ Local unemployment rate is computed at the census tract level. This variable provided a better fit than other alternative measures such as the distribution of working-age residents in the neighbourhood by citizenship, the distribution of working-age residents in the neighbourhood by education and the distribution of dwellings by age of construction.
} 
data is often a difficult task. Our choice was driven by data availability, together with what has been found elsewhere in the literature.

Family structure has been largely employed as an exclusion restriction for the employment equation in several empirical works. In this paper we follow the same strategy adopted by Devillanova (2013), who uses the number of adults in the family as an exclusion restriction for the employment equation. We assume that conditioning on car availability and on the set of covariates contained in the vector $X$, the number of adults in the family does not exert any direct effect on jobeducation mismatch and thus represents the main identifying variable for the employment equation. Moreover, the system's identification is reinforced by exploiting the detailed information about the presence of children in the household disaggregated by age groups. ${ }^{20}$ More specifically, we control for the whole number of children (aged from birth to 19) in the mismatch equation, whereas the employment equation includes different variables that capture the number of children by age group. The underlying assumption is that the presence of children in the family affects the risk of being mismatched only through long-standing factors related to childbearing, and employment decisions are more sensitive to short-term elements that are directly related to children's age. Finally, following Büchel and van Ham (2003) and Rubb (2014), age is included in the mismatch equation using a linear specification, capturing the fact that the divergence between individuals' occupation and educational attainments is likely to decrease over a career, whereas the other two equations contain a quadratic function of age.

Regarding the car equation, some studies have addressed the endogenous relationship of car ownership with labour market outcomes by adopting the standard Instrumental Variables approach. Raphael and Rice (2002) instrumented car ownership using insurance and gas tax costs and Ong and Miller (2005) used the cost of car ownership, the number of activities that can be conducted within the neighbourhood and the availability of alternative transportation as exclusion restrictions.

\footnotetext{
${ }^{20}$ Information about children has been used as an exclusion restriction in several studies in the context of wage regression and selection into employment (see, for example, Martins, 2001, Mulligan and Rubinstein, 2008, Lee, 2009 and Chang, 2011).
} 
The intrinsic difficulty of finding appropriate instruments for car availability (i.e. strong predictors of car availability unrelated to the final outcome of interest) is well recognised in the literature. The few exceptions are those studies that rely on exogenous changes in car ownership-related policies. For example, Baum (2009) controlled for potential endogeneity bias by jointly estimating employment and car ownership in a maximum likelihood framework, using differences in state vehicle asset rules governing welfare eligibility as instruments to identify the effect of car ownership. Bansak et al. (2010), referring to the same context, estimated a two-stage least square equation instrumenting car ownership with asset-related welfare.

In this paper, the available variables that were selected as exclusion restrictions for the car equation are the following. We consider an indicator that takes the value of one if there is a car park in the household building (without being necessary a property of the family), which should increase the propensity to acquire a car without affecting labour market outcomes directly. Moreover, the household's usable space is also included as an identifying variable in the car equation, on the assumption that it proxies wealth-related aspects that are positively related to car availability but conditionally orthogonal to job-education mismatch. However, to the best of our knowledge, there is still no formal way of testing for the validity of over-identifying restrictions ${ }^{21}$ in this threeequation framework with sample selection. Therefore, caution should be exercised when one reads the results that follow as true causal effects (rather than conditional correlations), since this definitively depends on assumptions that cannot be directly tested from the data.

There is an additional issue that should be taken into consideration. Our empirical strategy is based on the assumption that, conditional on other covariates and on car availability, public transport accessibility represents an exogenous variable. However, the associated coefficient may

\footnotetext{
${ }^{21}$ Since these two variables could indeed relate to mismatch through unobserved neighbourhood effects (uncaptured by local unemployment rates), we "informal" tested for instruments' validity by estimating the mismatch equation using Two-Stage Least Square (in which we treated the number of cars as continuous) and performing the Hansen J test for overidentification. The test does not reject the null hypothesis that the two variables can be plausibly excluded from the mismatch equation at any conventional significance level (results available upon request). This evidence can be (informally) taken as suggestive of the validity of the exclusion restrictions in the car equations.
} 
reflect, at least to some extent, endogenous residential sorting. This means that individuals who are intrinsically more likely to be employed and less likely to be mismatched may be more prone to reside in areas endowed with better public transport networks (for a detailed review of the issue of endogenous residential sorting, see Dujardin et al., 2009). Åslund et al. (2010) suggested that endogenous residential sorting affects the relationship between job proximity and labour market outcomes. Using a (very specific) sample of Swedish refugees, they solved this problem by exploiting a natural experiment generated by a refugee policy that randomly assigned individuals to places of residence and showed that job accessibility still matters (even under random residential sorting). Unfortunately, we were unable to deal directly with this issue, mostly because of the lack of exogenous predictors of job accessibility on public transport. However, in the subsection on robustness checks that is reported in the Appendix, we show additional results that can be taken as falsification tests for the relevance of residential sorting in the relationship between public transport accessibility and our outcomes of interest. Specifically, we first repeat all the estimations only for those individuals who did not change their residence in at least the last 10 years, for whom place of residence can be reasonably assumed to have been exogenous at the time of the survey. Second, we estimate the three equations only for those individuals who live with their parents (following Ihlanfeldt, 2006 and Dujardin et al., 2008, among others), since their place of residence within the urban area is mostly determined by their parents. Although in these cases better public transport accessibility might also capture long-standing unobserved family characteristics that are positively related to labour market outcomes, similar results in these additional estimations could be taken as evidence of the meaningfulness of our results (at least in qualitative terms).

\section{5) Results}


The results that we obtained from the three-equation system are reported in Table 2 . The model has been separately estimated for males and females. In this way we account for differential labour attachment by gender, differences in employment selectivity and, more importantly, any possible heterogeneous effect of car availability and public transport accessibility on employment and mismatch between males and females. We first briefly comment on the estimates associated with the control variables included in each equation, which are in line with the results previously obtained in the literature, and then discuss in more detail the results regarding car availability and job accessibility by public transport. Finally, the Appendix contains the results of several sensitivity analyses that are aimed at highlighting the robustness of our results with respect to a) the potential endogeneity of residential decisions, b) the fact that car ownership decisions are taken at the family level and c) the inclusion of an additional measure of employment potential defined in terms of private transport time.

\section{1) Estimates for Control Variables}

The results from the car equation show that, as expected, better educated individuals tend to have more cars (keeping family structure fixed), with similar effects for males and females. Car availability is lower for immigrants than for natives, especially among those born outside Europe. Moreover, bigger families are more likely to have more cars, as highlighted by the coefficients associated with being married, the number of children (especially children aged 16 to 19) ) $^{22}$ and the number of adults in the family. The estimates associated with household variables indicate that house size and disposing of a car park have a significant and positive effect on car availability. Regarding neighbourhood variables, individuals who reside in the capital city are less likely to have more cars in the family. Moreover, residents in areas with higher unemployment rates have fewer

\footnotetext{
${ }^{22}$ Unlike those in other studies (see Nolan, 2010, for instance), our data do not support a positive effect of the presence of young children in the household. This result was also obtained by Matas and Raymond (2008) for car ownership in Spain by using a different dataset.
} 
cars, reflecting the general idea that residential segregation is often accompanied by insufficient private transport connectivity.

The employment equation estimates highlight that age has the common U-shaped effect on employment probability for both men and women and is slightly more pronounced for the former. Educational attainments represent a fundamental determinant of the chances of being employed and that schooling may mitigate the differences in employment observed between males and females since the coefficients (and the corresponding marginal effects - not shown) associated with each education level are significantly higher for females than for males. The effect of marital status is, as expected, inverted between males and females, since married males are more likely to be employed, whereas the opposite result is obtained for females. The increase in the number of adults in the family is negatively related to employment probabilities for both genders. Finally, keeping fixed the number of adults in the family, we found that the presence of children is strongly detrimental for employment among females, with a negative effect that is inversely related to children's age because of childbearing activity. As usually reported in the literature, residing in a neighbourhood with a higher incidence of unemployment reduces employment probabilities, with a stronger effect for females (computed as a marginal effect on the predicted probabilities - not shown), whereas living in the capital city has a positive and statistically significant effect on employment probabilities only among females.

The general evidence obtained from the job-education mismatch equation, which has been estimated by controlling for self-selection into employment and car ownership's endogeneity, are in line with the results reported in the literature about mismatch. The estimates highlight that better educated individuals are, all other factors remaining constant, increasingly exposed to the risk of having more education than is required in their occupation (i.e. they are more likely to be overeducated). However, the incidence and the amount of mismatch among university graduates is fairly heterogeneous across different fields of study, since (compared with graduates in social sciences) 
the difference between individuals' education and the occupation average is significantly lower for graduates of health disciplines (mostly because of the stringent regulation of health-related professions) and, to a lesser extent, for male graduates of technical studies. Conversely, male and female graduates in applied science are somewhat more exposed to mismatch than their counterparts who study social sciences. Job-education mismatch decreases with age, which could be explained by both career progression for more tenured workers and/or by the impact of changes in the cohort/education composition of the workforce. Immigrant workers in general suffer a greater degree of mismatch, with the exception of those coming from EU15 countries, who are less likely to be more qualified than average for their occupations.

\section{2) The Effect of Public Transport Accessibility and Car Ownership}

We now focus in more detail on the estimates associated with the main variables of interest to this paper, i.e. car availability and job accessibility by public transport. To facilitate interpretation of the results, we directly describe the marginal effects on the three outcomes. Regarding public transport accessibility, we compute the percentage change in the outcome(s) after a $10 \%$ increase in accessibility. The marginal effects of car ownership are calculated as the percentage changes in outcome(s) associated with the availability of additional cars (i.e. changes from no to one car and from one to two cars or more). When considering the impacts on mismatch, we present the results expressed in terms of percentage change in years of 'over-education', which is defined as the (predicted) number of years of schooling in excess of the occupation average plus one standard deviation point. ${ }^{23}$ This focus is also motivated by the fact that, as noted above, being over-educated represents the most detrimental mismatch situation in terms of its detrimental effect on productivity,

\footnotetext{
${ }^{23}$ More specifically, instead of obtaining the effect on the whole distribution of the continuous mismatch variable, we computed the percentage difference between the sum of the 'observed' number of years of over-education (i.e. years of education that exceed the average schooling for the individual's occupation plus one standard deviation point) and the sum of the years of 'predicted' mismatch that exceeds the respective standard deviation after a $10 \%$ increase in public transport accessibility. Note that, in order to ensure comparability between the observed and the predicted amount of over-education, we imputed the residuals of the mismatch equation to the predicted mismatch resulting from a $10 \%$ change in public transport accessibility.
} 
earnings, job satisfaction and quitting intentions (and hence can be viewed as a form of underemployment).

First, the negative effect of public transport accessibility on the number of cars in the family that emerged in the raw data is also present once the effect of other covariates has been partialled out. In fact, the negative and relatively high elasticity of car availability with respect to public transport accessibility confirms that public and private transport represent substitute (albeit imperfect) ways of reaching job opportunities and that individuals residing in areas endowed with better public transport networks have fewer incentives to have more cars in the household.

Regarding the employment equation, it appears that among females the probability of being regularly employed is especially sensitive to car availability, with a slightly increasing effect for the change from one to two cars in the family. Moreover, even controlling for car ownership, we found that the increase in public transport accessibility has a significant and sizeable effect on the likelihood of being employed. This evidence confirms the findings reported by Matas et al. (2010). The results for the male subsample show that they are positively affected by car availability, but the main (modest) increase in employment probability is produced when they move from no to one car. Contrary to what happens among females, however, public transport accessibility to the workplace seems to be unrelated to male employment.

Moving to the main outcome of interest in this paper, the results indicate that job-education mismatch and in particular the extent of over-education in the labour market is negatively affected by car availability, as also reported by Büchel and Van Ham (2003) and by Ramos and Sanromà (2013). Moreover, the impact of car ownership on surplus schooling (relative to the individual's occupation) is somewhat stronger for females than for males. Regarding transit connectivity to potential jobs, the results indicate that the improvement in public transport accessibility to the workplace is significantly associated with less over-education in Barcelona's urban area, with a similar impact for males and females. Therefore, the amount of human capital that would be 
prevented from being wasted after an improvement in potential connectivity from places of residence to employment centres by public transport is relevant. Given the validity of the underlying assumptions behind the econometric model, this result shows that fostering job accessibility by improving the public transport network could be a sensitive route to follow in order to enhance the correct allocation of human capital in the local economy.

It also seems worth noting that the estimated correlations between the error terms of the three equations are in general significant ${ }^{24}$ and are in the same direction for both males and females, which means that the interrelation between the unobservable elements that affect car availability, employment and job-education mismatch should be taken into account in order to obtain a consistent estimate of the impact of public transport job accessibility on job-education mismatch, controlling for (endogenous) car availability and self-selection into employment. For comparison purposes, we also report the estimated marginal effects of car ownership and public transport accessibility that are obtained on the assumption that the three equations are independent (see Table A3 in the Appendix). This exercise suggests that, although taking into account the correlation among unobservable determinants of the three equations is relevant in this context (and should be taken as reference for a quantitative interpretation of the results), the evidence produced by independent equations is in the same direction and highlights the robustness of the overall results regarding the relationship between public transport job accessibility and labour market outcomes.

\section{6) Conclusions}

In this paper we have analysed the effect of spatial connectivity to job opportunities on the extent of job-education mismatch in an urban labour market. We specifically focused on the metropolitan area of Barcelona, which has experienced a job and residential decentralisation

\footnotetext{
${ }^{24}$ The exception is the correlation between unobservables of the cars and employment equations among males, which is not statistically different from zero.
} 
process since the 1990s. The incidence and the extent of over-education (i.e. the surplus of schooling relative to an individual's occupation) could, among other things, be the result of a spatially constrained job search. Therefore, fostering spatial connectivity to potential employment centres is likely to be beneficial for a better allocation of human capital in the local economy. We approximated physical job accessibility to potential job opportunities in two distinct ways. First, as usually done in the literature, we considered car availability to be an important determinant of mismatch. Second, we also enabled for a separate effect of public transport job accessibility on jobeducation mismatch. Therefore, this is the first paper concerned with the importance of public transport connectivity in explaining the extent of mismatch between individuals' educational attainment and the educational requirement in their jobs, with a specific focus on a metropolitan labour market.

With the aim of obtaining the direct effect of public transport accessibility and car availability, we specified a joint model for car ownership and job-education mismatch that enables transit connectivity to be a determinant of car availability as well. Moreover, we also controlled for employment selectivity, since the mismatch variable is observed only for those who are regularly employed. Our methodological framework is also innovative, since it relies on a simultaneous system of equations with a recursive structure. The estimations were carried out separately for males and females, in order to check for gender differences in the impact of public and private transport accessibility to the workplace, accounting for differences in labour market attachment and employment selectivity.

The evidence obtained in this paper confirms the existing results regarding car availability, which is associated with a reduction in the surplus schooling in the local economy. The results suggest that having access to private vehicles is somewhat more important for women than for men in terms of explaining the match between education and occupation (as well as employment probability). However, private transport is not the only element of spatial flexibility that matters. In 
fact, public transport job accessibility to potential employment centres has a significant and sizeable direct effect on reducing surplus schooling, even accounting for the existing relationship of transit connectivity with car ownership and employment. Moreover, public transport has a similar effect for males and females, although the latter are likely to be more dependent on public transport and to have less access to cars within the family. Additional robustness checks indicate that our results are not driven by the potential endogeneity of residential sorting. ${ }^{25}$ Therefore, it is possible to argue that enhancing spatial flexibility by favouring car access and improving transit connectivity between residential locations and potential job opportunities is beneficial for the match between education and occupation, since it implies a reduction of job-search opportunity costs in urban labour markets.

Therefore, the general implication of this study is that public policies that are designed to reduce commuting costs will help to improve employment and job quality. However, the processes of both urban sprawl and employment decentralisation of the Barcelona's metropolitan area took place in a context of weak metropolitan-wide planning. This growth pattern represents an important challenge in the development of an efficient (and cost-effective) public transport network that can satisfy transport needs, especially for working-related trips that take place outside central cities. Indeed, individuals who have to commute from residential areas to low job-density areas are more and more car-dependent. Therefore, although our results favour public policies aimed at increasing public transport accessibility - especially in the light of the environmental sustainability of public transport in dense urban areas - urban planners cannot disregard that having access to a car could be crucial for reaching jobs located at the periphery of the city.

\section{References}

\footnotetext{
${ }^{25}$ Moreover, we have also shown that controlling for car availability, including a variable that captures potential job accessibility by private transport, barely affects labour market outcomes and does not undermine the relevance of public transport connectivity to job opportunities. This result can be explained by the fact that within Barcelona's urban area most employment centres can be easily reached (at least) by private transport, but also reinforces the idea that public transport accessibility is relevant for job-education match (keeping fixed the spatial connectivity to employment by private vehicles).
} 
Åslund, O., Östh, J., Zenou, Y. (2010) How important is access to jobs? Old question--improved answer. Journal of Economic Geography 10(3): 389-422.

Bansak, C., Mattson, H., Rice, L. (2010) Cars, Employment, and Single Mothers: The Effect of Welfare Asset Restrictions. Industrial Relations 49(3): 321-45.

Baum, C.L. (2009) The effects of vehicle ownership on employment. Journal of Urban Economics 66(3): 151-163.

Büchel, F., Battu, H. (2003) The theory of differential overqualification: Does it work? Scottish Journal of Political Economy, 50(1): $1-16$.

Büchel, F. M., Van Ham (2003) Overeducation, Regional Labour Markets and Spatial Flexibility. Journal of Urban Economics, 53: 482-493.

Bunel, M., Tovar, E. (2013) Key Issues in Local Job Accessibility Measurement: Different Models Means Different Results. Urban Studies, on-line first (DOI: 10.1177/0042098013495573).

Chang, S.K. (2011) Simulation estimation of two-tiered dynamic panel Tobit models with an application to the labor supply of married women. Journal of Applied Econometrics, 26: 854-871.

Combes, P.P., Gobillon, L. (2015) The Empirics of Agglomeration Economies. In: Duranton G., Henderson V., Strange W. (eds) Handbook of Regional and Urban Economics, vol. 5 (forthcoming). Elsevier, Amsterdam.

Croce, G., Ghignoni, E. (2015) Educational mismatch and spatial flexibility in Italian local labour markets. Education Economics, 23(1): $25-46$

Devillanova, C. (2013) Overeducation and spatial flexibility: New evidence from Italian survey data. Papers in Regional Science, 92(3): 445-464.

Dujardin, C., Selod, H., Thomas, I. (2008). Residential segregation and unemployment: the case of Brussels. Urban Studies, 45(1): 89-113.

Dujardin, C., Peeters, D., Thomas, I. (2009) Neighbourhood effects and endogeneity issues. In: Bavaud, F. and Mager, C. (eds.), Handbook of Theoretical and Quantitative Geography. Université de Lausanne, Lausanne.

Flisi, S., Goglio, V., Meroni, E., Rodrigues, M., Vera-Toscano, E. (2014) Occupational mismatch in Europe: understanding overeducation and overskilling for policy making. JRC scientific and technical reports no. JRC89712 (DOI: 10.2788/61733), Publications Office of the European Union (available at http://publications.jrc.ec.europa.eu/repository/handle/JRC89712).

Gautier, P.A., Zenou, Y. (2010) Car ownership and the labour market of ethnic minorities. Journal of Urban Economics, 67: 392403.

Gobillon, L., Selod, H., Zenou, Y. (2007) The mechanisms of spatial mismatch. Urban Studies, 44: 2401-2427.

Gobillon, L., Selod, H. (2008) Les determinants lacaux du chômage en regions parisienne. Economie et Prevision, 4: 419-438.

Gobillon, L., Selod, H. (2014) Spatial mismatch, poverty, and vulnerable populations. In: Fisher, M., Nijkamp P. (eds.) Handbook of Regional Science, vol. 1. Springer-Verlag, Heidelberg.

Leuven, E., Oosterbeek, H. (2011) Overeducation and Mismatch in the Labor Market. In: Hanushek, E., Welch, F. (eds) Handbook of the Economics of Education, vol. 4. Elsevier, Amsterdam.

Hartog, J. (2000) Over-education and earnings: where are we, where should we go? Economics of Education Review, 19(2): 131-147.

Hensen, M.M., De Vries, M.R. , Cörvers, F. (2009) The Role of Geographic Mobility in Reducing Education-job Mismatches in the Netherlands. Papers in Regional Science, 88: 667-682.

Holzer, H. J., Quigley, J. M., Raphael, S. (2003) Public transit and the spatial distribution of minority employment: evidence from a natural experiment. Journal of Policy Analysis and Management, 22: 415-423.

Jauhiainen, S. (2011) Overeducation in the Finnish regional labour markets. Papers in Regional Science, 90: 573-588.

Iammarino. S., Marinelli, E. (2014) Education-Job (Mis)Matching And Interregional Migration: Italian University Graduates' Transition To Work. Regional Studies, forthcoming (DOI: 10.1080/00343404.2014.965135). 
Ihlanfeldt, K., Sjoquist, D. (1998) The spatial mismatch hypothesis: a review of recent studies and their implications for welfare reform. Housing Policy Debate 9: 849-892.

Ihlanfeldt, K. (2006) A primer on spatial mismatch within urban labor markets. In: Arnott, R. J., McMillen, D.P. (eds) A Companion to Urban Economics. Blackwell Publishing, Oxford.

Kain, J. (1968) Housing segregation, Negro employment, and metropolitan decentralization. Quarterly Journal of Economics, 82: 175-197.

Kawabata, M. (2003) Job access and employment among low-skilled autoless workers in US metropolitan areas. Environment and Planning A, 35: 1651-1668.

Korsu, E., Wenglenski, S. (2010) Job accessibility, residential segregation and risk of long-term unemployment in Paris Region. Urban Studies, 47: 2279-2324.

Lee, D.S. (2009) Training, Wages, and Sample Selection: Estimating Sharp Bounds on Treatment Effects. Review of Economic Studies, 76: 1071-1102.

Leuven, E., Oosterbeek, H. (2011) Overeducation and Mismatch in the Labor Market. In: Hanushek, E., Welch, F. (eds) Handbook of the Economics of Education, vol. 4. Elsevier, Amsterdam.

Matas, A, Raymond, J.L (2008) Changes in the structure of car ownership in Spain, Transportation Research Part A: Policy and Practice, 42(1): 187-202

Matas, A., Raymond, J.L., Roig, J.L (2010) Job Accessibility and Female Employment Probability: The Cases of Barcelona and Madrid. Urban Studies, 47(4): 769-787.

McGuinness, S. (2006) Overeducation in the Labour Market. Journal of Economic Surveys, 20(3): 387-418.

Martins, M. (2001) Parametric and Semiparametric Estimation of Sample Selection Models: An Empirical Application to the Female Labour Force in Portugal. Journal of Applied Econometrics, 16: 23-39.

Mulligan, C. B., Rubinstein, Y. (2008) Selection, Investment, and Women's Relative Wages Over Time. Quarterly Journal of Economics, 123: 1061-1110.

Nolan, A. (2010) A dynamic analysis of household car ownership, Transportation Research Part A: Policy and Practice, 44(6): 446455 .

Norman, T., Börjesson, M. Anderstig, C. (2012) How does changing job accessibility affect the employment rate? Unpublished document (available at:

http://indico.conferences.dtu.dk/getFile.py/access?contribId=102\&sessionId=24\&resId=0\&materialId=paper\&confId=133)

Ong, P.M., Miller, D. (2005) Spatial and Transportation Mismatch in Los Angeles. Journal of Planning Education and Research, 25 : 43-56.

Patacchini, E., Zenou, Y. (2005) Spatial mismatch, transport mode and search decisions in England. Journal of Urban Economics, 58: 62-90.

Ramos, R., Sanromà, E. (2013) Overeducation and Local Labour Markets in Spain. Tijdschrift voor Economische en Sociale Geografie, vol. 104 (3), pp. 278-291.

Raphael, S., Rice, L. (2002) Car ownership, employment, and earnings. Journal of Urban Economics, 52(1): 109-130.

Rogers, C. (1997) Job search and unemployment duration: implications for the spatial mismatch hypothesis. Journal of Urban Economics, 42: 109-132.

Roodman, D. (2011) Fitting fully observed recursive mixed-process models with cmp. Stata Journal, 11(2): 159-206.

Rubb, S. (2014) Factors influencing the likelihood of overeducation: a bivariate probit with sample selection framework. Education Economics, 22(2): 1-28.

Sanchez, T. W. (1999) The connection between public transport and employment: the cases of Portland and Atlanta. Journal of the American Planning Association, 65: 284-296. 
Verhaest, D., Omey, E. (2006) The Impact of Overeducation and its Measurement. Social Indicators Research, 77(3):419-448.

Zenou, Y., (2008) The spatial mismatch hypothesis. In: Blume, L., Durlauf, S. (eds.) The New Palgrave Dictionary of Economics, second edition. MacMillan Press, London.

Supporting Information Additional Supporting Information may be found in the online version of this article at the publisher's web-site:

http://onlinelibrary.wiley.com/journal/10.1111/\%28ISSN\%291435-5957

Supplementary Material: Appendix to "JOB ACCESSIBILITY AND JOB-EDUCATION MISMATCH IN THE METROPOLITAN AREA OF BARCELONA”

\section{APPENDIX}

\section{A1) Sensitivity Analysis}

In order to provide additional evidence in favour of the meaningfulness of the results presented in this paper, we performed several robustness checks of our estimates. As previously observed, we are especially concerned about the exogeneity of our measure of public transport accessibility, since it could be argued that it is mostly driven by endogenous residential sorting ${ }^{26}$ (see Dujardin et al., 2009). Unfortunately, we do not possess exogenous predictors of public transport accessibility that would enable its instrumentation, and arguing that people randomly select their place of residence seems rather implausible. However, we performed two robustness checks in this regard, which taken together should indicate whether (or not) the conditional relationship between public transport accessibility and labour market outcomes is simply a mirror of endogenous residential sorting. Basically, we seek to replicate the analysis for different subsamples of individuals for whom place of residence can be taken as exogenous with respect to labour market outcomes. First, following

\footnotetext{
26 Notice that, to some extent, endogenous residential sorting could also be related to car ownership decisions. Therefore, in the following robustness checks we also report the coefficients for car availability, in order to show that residential sorting is not biasing the corresponding estimates.
} 
Matas et al. (2010), we re-estimate the system of equations restricting the sample to individuals who have not changed their place of residence in at least the last 10 years. Second, following Ihlanfeldt (2006) and Dujardin et al. (2008), we consider individuals who still live with their parents to have rather limited influence on residential choices. Therefore, the relationship between public transport accessibility and labour market outcomes obtained by selecting this specific subsample should be less contaminated by the endogeneity of residential sorting. The results of these two alternative exercises are reported in Table A4 (we only report the marginal effect on years of over-education), together with the baseline results for comparison. With the aim of facilitating the interpretation of these additional results, the descriptive statistics of these two special subsamples are shown in Table A5 in this Appendix.

From a qualitative perspective, the results are rather similar to those obtained in the baseline estimations, again suggesting that improving spatial connectivity to employment locations would reduce the amount of positive (and severe) mismatch (i.e. over-education). More specifically, the estimated marginal effects obtained from the subsample of individuals who did not change their residential location during the decade prior to the Census survey are slightly higher than those obtained from the original estimating sample in the case of public transport accessibility and slightly lower for car ownership. When we instead restrict the sample to young individuals who still reside with their parents, the elasticity of years of over-education with respect to transit accessibility obtained for men is virtually the same as the baseline estimate, whereas the effect of car availability is a little lower. However, the effect of public transport accessibility detected for women is somewhat reduced, but still negative and significant. Therefore, the main message that we can derive from these two additional estimations is that endogenous residential sorting, even if it happens, does not seem to be the main explanation for the overall evidence reported in this paper. ${ }^{27}$

\footnotetext{
${ }^{27}$ We recognise that the two falsification strategies followed in this study are not immune to criticisms. In fact, unobserved family characteristics related to residential location might still affect both subgroups of workers if 1) these represent long-standing elements and/or 2) they are transmitted from parents to children and are shared within the family. Moreover, some kind of endogenous sample-
} 
We also performed an additional sensitivity check concerned with the fact that car ownership decisions are taken at the family level and the sample contains repeated observations within each family. The most suitable option would be to estimate the car equation at the family level, but this would introduce further complications in estimation of the system of equations. ${ }^{28}$ Therefore, we repeated the analysis using only observations from individuals who declared that they are the head of the household. The marginal effects of car ownership on the amount of surplus schooling are also reported in the bottom panel of Table A4 for both males and females. In this case, the marginal effects of car availability on the surplus schooling are somewhat higher for males, but slightly lower for females (relative to the baseline), which could be the result of different labour market attachment among men and women who are householders. Moreover, the result obtained for females who are in charge of their family could arise because of the peculiar situation of this subsample, which represents a relatively unusual situation in Spanish reality.

Finally, we carried out another sensitivity analysis that is more specifically concerned with the underlying concept of job accessibility. In this paper accessibility to potential employment centres is captured in two distinct ways. On the one hand, as previously done in the literature, we considered car availability as a proxy for accessibility by private transport. On the other hand, we specified accessibility by public transport using a measure of employment potential - relative to public transport time. However, it could be argued that our public transport job accessibility measure is actually capturing general job accessibility rather than the specific effect of public transport network's connectivity to job locations. ${ }^{29}$ In order to show that the way in which we capture public transport accessibility is meaningful and matters for job-education mismatch

\footnotetext{
selection may be present, especially among young individuals living with their parents. However, the observation of qualitatively similar results to those obtained with the whole sample is reassuring in terms of the robustness of our empirical analysis.

28 Another option which takes into account how car availability is the same for each individual belonging to the same household could be to cluster the standard error at the family level. However, this could only be applied to households with more than one member in the sample, which would introduce selection bias (especially because we split the sample between males and females).

29 We acknowledge the interesting suggestions received from two anonymous referees on this point, which inspired this additional sensitivity exercise.
} 
regardless of general accessibility to workplaces, we constructed another accessibility measure in the same vein as the variable of interest but using private transport time rather than public transport time. Therefore, we estimated again the system of equations, augmenting the mismatch and employment equation with this additional private transport accessibility measure. Selected results are reported in Table A6 in this Appendix. Column (a) contains the baseline results for comparison, and in column (b) displays the estimates obtained including this additional measure of employment potential relative to private transport time.

As can be appreciated, once we control for public transport connectivity and car availability, job accessibility by private transport is barely significant and has a very modest impact on labour market outcomes. This result can be explained by the fact that within Barcelona's urban area most of the employment centres can be easily reached (at least) by private transport. More importantly, the estimates of public transport accessibility to the workplace and car availability are almost unaffected by the inclusion of the additional accessibility variable. The overall evidence obtained from the above sensitivity exercises reinforces the relevance of the present study, which sheds light on the importance of public transport accessibility as an additional way to increase spatial flexibility of workers in urban labour markets, on top of the beneficial effect of private transport availability. 


\section{FIGURES}

Figure 1: Public Transport Job Accessibility in the Metropolitan Area of Barcelona

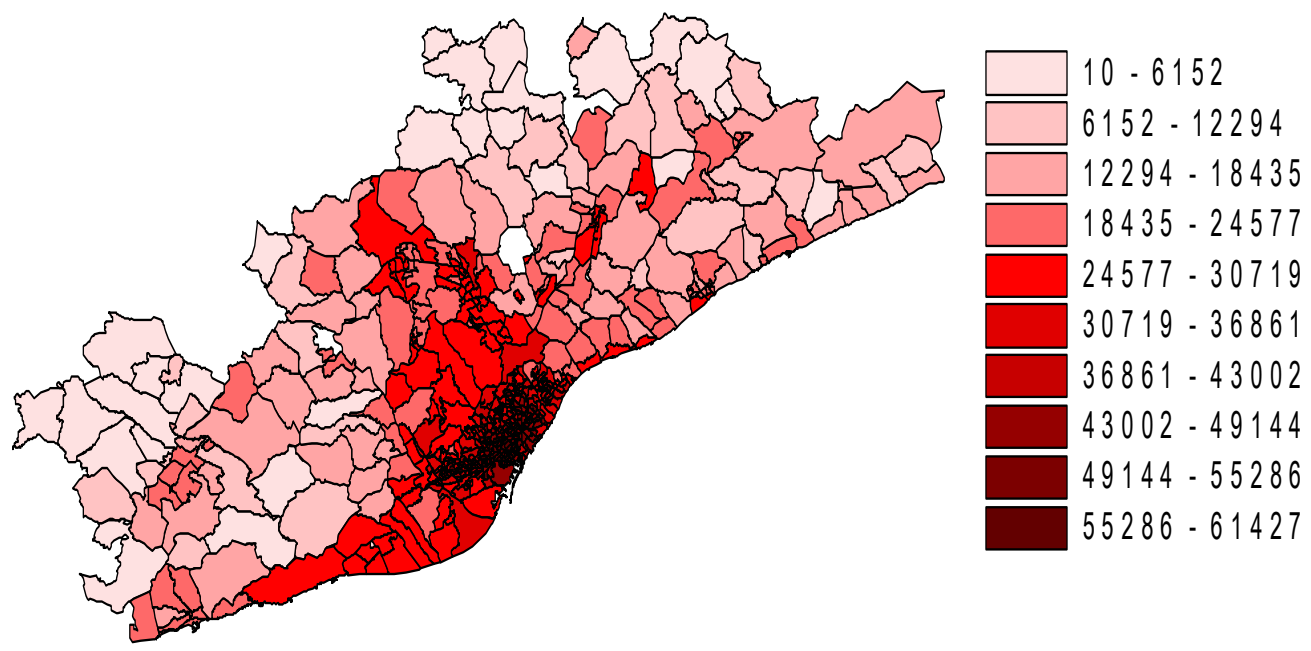

Source: Spanish Census of 2001, official public transport travel time matrixes (transport zone level) and authors' calculations. The number of jobs and destination zones have been defined at the municipality level and at the district level within the city of Barcelona.

Figure 2: Spatial Employment Density in the Metropolitan Area of Barcelona (number of jobs per $\mathrm{Km}^{2}$ )
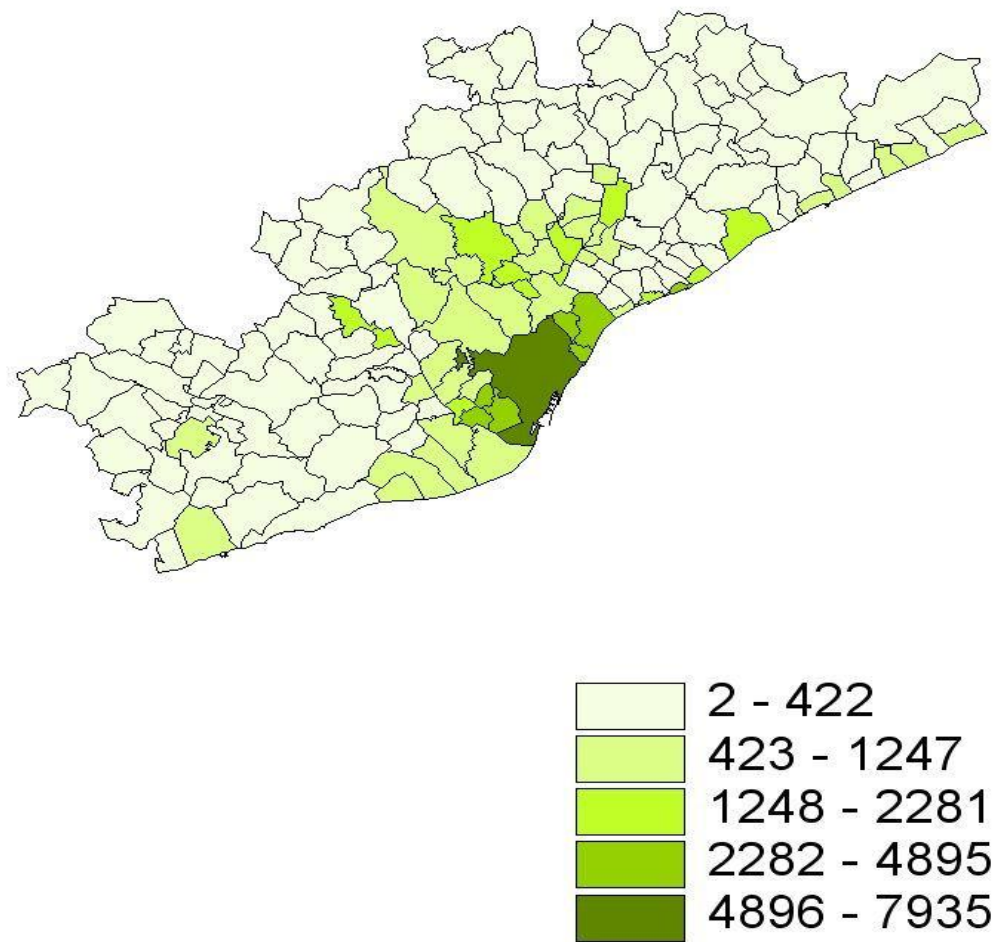

Source: Spanish Census of 2001. The number of jobs has been defined at the municipality level and at the district level within the city of Barcelona. 
Figure 3: Public Transport Accessibility and Number of Cars in the Household

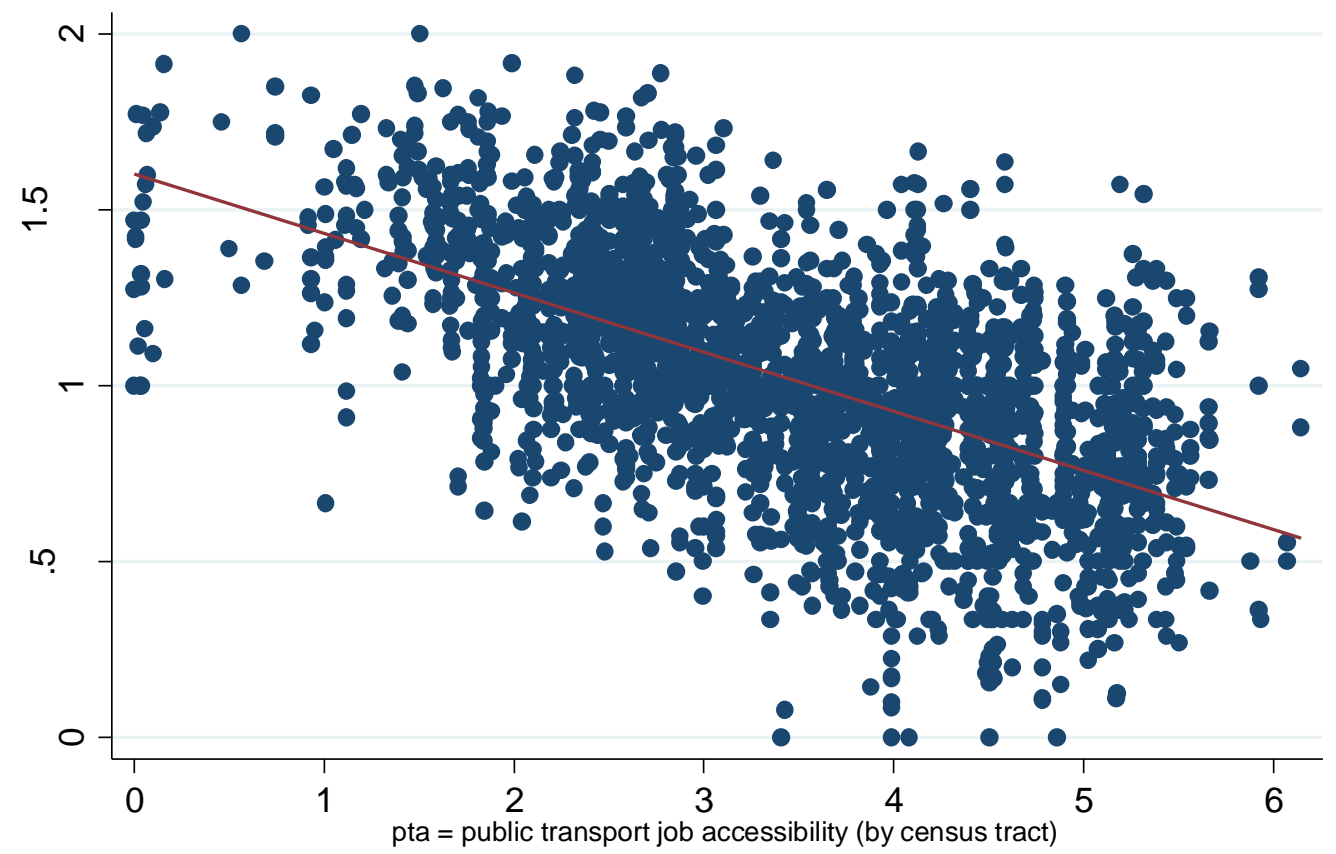

- cars $=1.6-0.170 \cdot p t a(R$-squared $=0.35) \quad$ Fitted values 


\section{TABLES}

Table 1: Public Transport Accessibility, Car Ownership, Employment and Job-Education Mismatch

\begin{tabular}{|c|c|c|c|c|c|c|c|c|c|}
\hline & & & & Males & Females & Males & Females & Males & Females \\
\hline public transport accessibility (pta) & cars $=0$ & cars $=1$ & cars $\geq 2$ & \multicolumn{2}{|c|}{ \% employed } & \multicolumn{2}{|c|}{ average mismatch } & \multicolumn{2}{|c|}{ \% overeducated } \\
\hline quintile 1 & 9.94 & 46.57 & 43.49 & 89.89 & 56.88 & -0.230 & -0.061 & 14.25 & 14.69 \\
\hline quintile 2 & 12.20 & 52.12 & 35.68 & 89.90 & 57.22 & -0.251 & -0.096 & 14.62 & 14.52 \\
\hline quintile 3 & 16.47 & 54.45 & 29.08 & 89.33 & 56.49 & -0.157 & -0.006 & 15.66 & 15.59 \\
\hline quintile 4 & 25.05 & 56.63 & 18.32 & 87.48 & 57.50 & -0.049 & 0.186 & 17.17 & 17.24 \\
\hline quintile 5 & 32.74 & 54.27 & 12.99 & 87.83 & 64.98 & 0.367 & 0.395 & 19.61 & 20.50 \\
\hline \# of cars in the household (cars) & & & & \multicolumn{2}{|c|}{ \% employed } & \multicolumn{2}{|c|}{ average mismatch } & \multicolumn{2}{|c|}{ \% overeducated } \\
\hline cars $=0$ & & & & 80.32 & 59.89 & -0.39 & -0.05 & 14.21 & 15.78 \\
\hline cars $=1$ & & & & 90.22 & 56.94 & -0.11 & 0.07 & 16.13 & 16.60 \\
\hline cars $\geq 2$ & & & & 91.85 & 61.10 & 0.18 & 0.25 & 17.38 & 17.35 \\
\hline Total & 19.24 & 52.8 & 27.96 & 88.90 & 58.65 & -0.07 & 0.10 & 16.19 & 16.65 \\
\hline
\end{tabular}

Note: mismatch represents the difference between years of schooling and average years of schooling in the corresponding occupations. Overeducated is an indicator variable that takes the value of one in the case the individuals has more schooling that the occupational mean plus one standard deviation point. 
Table 2: Three-Equation System Estimates

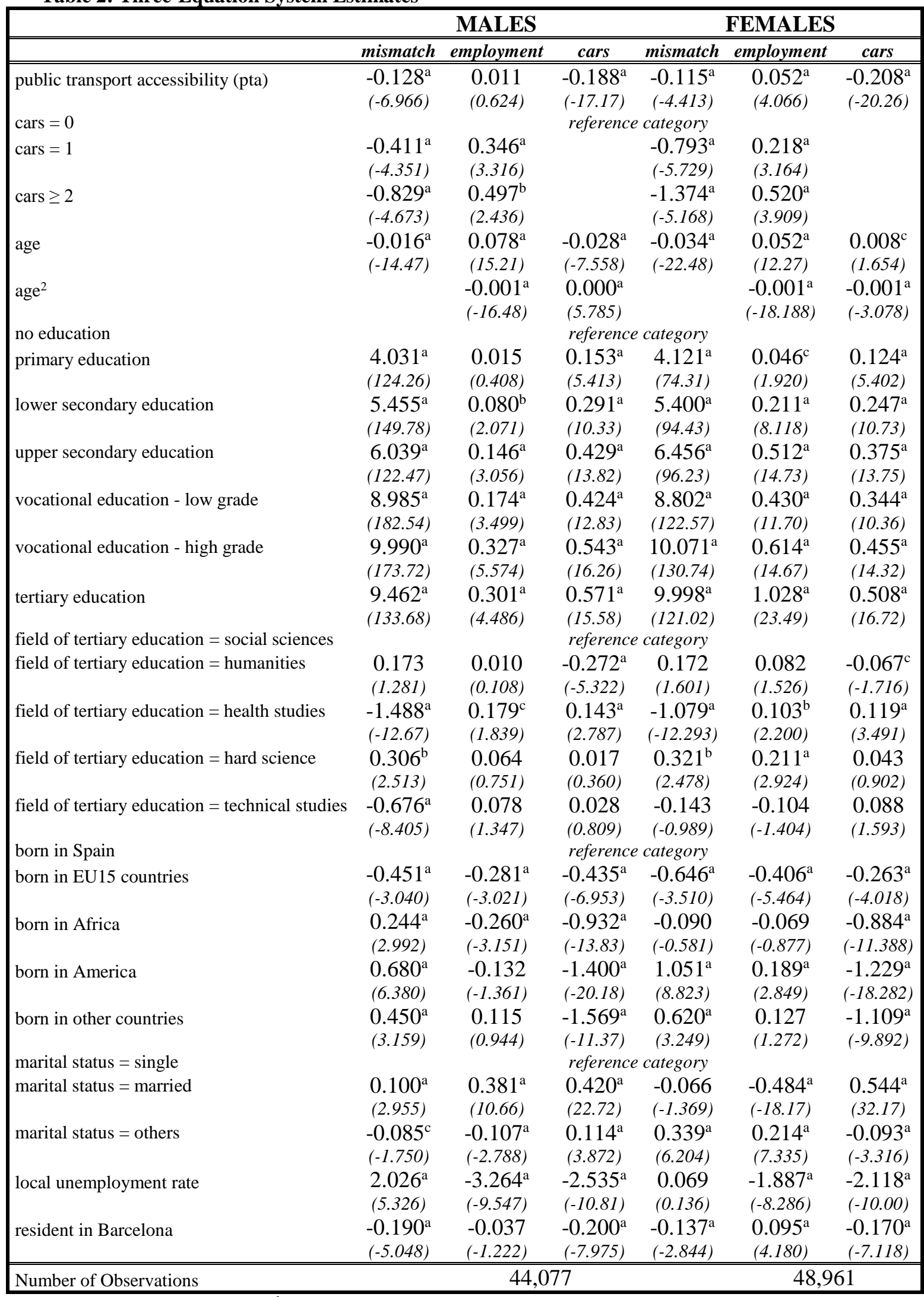

Note: ${ }^{a}$ significant at $1 \%$ level, ${ }^{b}$ significant at $5 \%$ level, ${ }^{c}$ significant at $10 \%$ level; $t$-Statistics in parenthesis, standard errors clustered at the census-tract level. 
Table 2: Three-Equation System Estimates (continued)

\begin{tabular}{|c|c|c|c|c|c|c|}
\hline & \multicolumn{3}{|c|}{ MALES } & \multicolumn{3}{|c|}{ FEMALES } \\
\hline & mismatch & employment & cars & mismatch & employment & cars \\
\hline \# children aged 0-19 & $\begin{array}{c}-0.018^{\mathrm{c}} \\
(-1.660)\end{array}$ & & & $\begin{array}{c}-0.129^{a} \\
(-8.824)\end{array}$ & & \\
\hline \# children aged 0-4 & & $\begin{array}{l}-0.027 \\
(-1.092)\end{array}$ & $\begin{array}{l}0.029^{c} \\
(1.914)\end{array}$ & & $\begin{array}{l}-0.254^{\mathrm{a}} \\
(-15.04)\end{array}$ & $\begin{array}{l}0.040^{\mathrm{b}} \\
(2.375)\end{array}$ \\
\hline \# children aged 5-9 & & $\begin{array}{l}-0.009 \\
(-0.333)\end{array}$ & $\begin{array}{l}0.001 \\
(0.057)\end{array}$ & & $\begin{array}{l}-0.213^{a} \\
(-13.42)\end{array}$ & $\begin{array}{l}-0.018 \\
(-1.151)\end{array}$ \\
\hline \# children aged 10-15 & & $\begin{array}{l}-0.028 \\
(-1.296)\end{array}$ & $\begin{array}{l}0.028^{\mathrm{c}} \\
(1.788)\end{array}$ & & $\begin{array}{l}-0.133^{a} \\
(-9.356)\end{array}$ & $\begin{array}{l}0.011 \\
(0.709)\end{array}$ \\
\hline \# children aged 16-19 & & $\begin{array}{c}-0.041^{\mathrm{b}} \\
(-1.989)\end{array}$ & $\begin{array}{l}0.121^{\mathrm{a}} \\
(7.240)\end{array}$ & & $\begin{array}{l}-0.077^{\mathrm{a}} \\
(-5.422)\end{array}$ & $\begin{array}{l}0.115^{\mathrm{a}} \\
(7.215)\end{array}$ \\
\hline number of adults in the household & & $\begin{array}{c}-0.045^{\mathrm{a}} \\
(-3.351)\end{array}$ & $\begin{array}{l}0.199^{a} \\
(16.07)\end{array}$ & & $\begin{array}{c}-0.096^{\mathrm{a}} \\
(-5.588)\end{array}$ & $\begin{array}{l}0.214^{\mathrm{a}} \\
(7.206)\end{array}$ \\
\hline car park in the house building & & & $\begin{array}{l}0.166^{\mathrm{a}} \\
(8.360)\end{array}$ & & & $\begin{array}{l}0.178^{a} \\
(10.25)\end{array}$ \\
\hline usable housing space (in m²/100) & & & $\begin{array}{l}0.006^{\mathrm{a}} \\
(14.77)\end{array}$ & & & $\begin{array}{l}0.006^{\mathrm{a}} \\
(20.49)\end{array}$ \\
\hline constant & $\begin{array}{l}-5.220^{\mathrm{a}} \\
(-33.286)\end{array}$ & $\begin{array}{l}-0.211 \\
(-1.154)\end{array}$ & & $\begin{array}{l}-5.167^{a} \\
(-23.15)\end{array}$ & $\begin{array}{l}-0.125 \\
(-1.112)\end{array}$ & \\
\hline$\mu_{1}$ & & & $\begin{array}{c}-1.069^{a} \\
(-10.74)\end{array}$ & & & $\begin{array}{l}-0.271^{\mathrm{c}} \\
(-1.762)\end{array}$ \\
\hline$\mu_{2}$ & & & $\begin{array}{l}0.662^{\mathrm{a}} \\
(6.562)\end{array}$ & & & $\begin{array}{l}1.465^{\mathrm{a}} \\
(9.093)\end{array}$ \\
\hline$\rho_{\varepsilon, u}$ & & $\begin{array}{l}0.438^{\mathrm{a}} \\
(15.36)\end{array}$ & & & $\begin{array}{l}0.747^{\mathrm{a}} \\
(55.83)\end{array}$ & \\
\hline$\rho_{\varepsilon, v}$ & & $\begin{array}{l}0.136^{\mathrm{a}} \\
(4.072)\end{array}$ & & & $\begin{array}{l}0.179^{a} \\
(4.337)\end{array}$ & \\
\hline$\rho_{u, v}$ & & $\begin{array}{l}-0.048 \\
(-0.675)\end{array}$ & & & $\begin{array}{l}-0.138^{a} \\
(-2.980)\end{array}$ & \\
\hline Number of Observations & & 44,077 & & & 48,961 & \\
\hline
\end{tabular}

Note: ${ }^{a}$ significant at $1 \%$ level, ${ }^{b}$ significant at $5 \%$ level, ${ }^{c}$ significant at $10 \%$ level; $t$-Statistics in parenthesis, standard errors clustered at the census tract level. 
Table 3: Marginal Effects of Public Transport Accessibility and Car Ownership

\begin{tabular}{|c|c|c|c|c|c|}
\hline \multicolumn{6}{|c|}{ OUTCOME } \\
\hline & $\begin{array}{l}\% \Delta[\text { [years of } \\
\text { overeducation] }\end{array}$ & $\% \Delta \operatorname{Pr}[e m p l o y e d]$ & $\% \Delta \operatorname{Pr}[$ cars $=0]$ & $\% \Delta \operatorname{Pr}[$ cars $=1]$ & $\% \Delta \operatorname{Pr}[$ cars $\geq 2]$ \\
\hline \multicolumn{6}{|l|}{ MALES } \\
\hline$\% \Delta($ public transport accessibility) & -0.086 & 0.007 & 0.897 & 0.034 & -0.828 \\
\hline$\Delta 0$ to $1 \mathrm{car}$ & -0.076 & 0.087 & & & \\
\hline$\Delta 1$ to 2 cars & -0.084 & 0.027 & & & \\
\hline \multicolumn{6}{|l|}{ FEMALES } \\
\hline$\% \Delta$ (public transport accessibility) & -0.081 & 0.116 & 0.947 & 0.000 & -0.947 \\
\hline$\Delta 0$ to 1 car & -0.141 & 0.176 & & & \\
\hline$\Delta 1$ to 2 cars & -0.120 & 0.193 & & & \\
\hline
\end{tabular}

Note: the marginal effect of public transport accessibility is computed as the changes in predicted outcomes after a 10\% change in public transport accessibility (elasticity). The marginal effect of car ownership is the changes in predicted outcomes after switching from 0 to 1 car and from 1 to 2 cars respectively. The elasticity of the years of overeducation has been computed considering individuals to be overeducated when they have more years of schooling than the average in their respective occupation plus one standard deviation point (i.e. mismatch greater than the standard deviation of years of schooling in each occupation). Numbers in bold type indicate that the corresponding coefficient is significant at a 5\% significance level. 
TABLES FOR THE APPENDIX

Table A1: Descriptive Statistics by Gender

\begin{tabular}{|c|c|c|c|c|}
\hline & \multicolumn{2}{|c|}{ MALES } & \multicolumn{2}{|c|}{ FEMALES } \\
\hline & mean & s.d. & mean & s.d. \\
\hline public transport accessibility (pta) & 3.182 & 1.116 & 3.222 & 1.130 \\
\hline cars $=0$ & 0.180 & 0.384 & 0.198 & 0.399 \\
\hline cars $=1$ & 0.534 & 0.499 & 0.533 & 0.499 \\
\hline cars $\geq 2$ & 0.285 & 0.452 & 0.269 & 0.443 \\
\hline employed & 0.889 & 0.314 & 0.586 & 0.492 \\
\hline job-education mismatch (years) & -0.070 & 3.104 & 0.095 & 3.026 \\
\hline overeducation (schooling > occupation-average + s.d.) & 0.162 & 0.368 & 0.167 & 0.373 \\
\hline age & 38.31 & 11.93 & 40.33 & 11.98 \\
\hline no education & 0.062 & 0.242 & 0.087 & 0.281 \\
\hline primary education & 0.179 & 0.383 & 0.195 & 0.396 \\
\hline lower secondary education & 0.311 & 0.463 & 0.301 & 0.459 \\
\hline upper secondary education & 0.129 & 0.336 & 0.121 & 0.326 \\
\hline vocational education - low grade & 0.080 & 0.272 & 0.069 & 0.253 \\
\hline vocational education - high grade & 0.082 & 0.275 & 0.063 & 0.242 \\
\hline tertiary education & 0.156 & 0.363 & 0.165 & 0.372 \\
\hline field of tertiary education $=$ social sciences & 0.058 & 0.234 & 0.082 & 0.274 \\
\hline field of tertiary education $=$ humanities & 0.014 & 0.119 & 0.025 & 0.155 \\
\hline field of tertiary education $=$ health studies & 0.015 & 0.120 & 0.034 & 0.181 \\
\hline field of tertiary education $=$ hard science & 0.016 & 0.126 & 0.013 & 0.115 \\
\hline field of tertiary education $=$ technical studies & 0.052 & 0.223 & 0.011 & 0.106 \\
\hline born in Spain & 0.944 & 0.230 & 0.954 & 0.210 \\
\hline born in EU15 countries & 0.008 & 0.091 & 0.007 & 0.086 \\
\hline born in Africa & 0.020 & 0.140 & 0.010 & 0.098 \\
\hline born in America & 0.018 & 0.132 & 0.023 & 0.151 \\
\hline born in other countries & 0.010 & 0.099 & 0.006 & 0.079 \\
\hline marital status $=$ single & 0.388 & 0.487 & 0.264 & 0.441 \\
\hline marital status $=$ married & 0.560 & 0.496 & 0.650 & 0.477 \\
\hline marital status $=$ others & 0.053 & 0.224 & 0.086 & 0.280 \\
\hline local unemployment rate & 0.111 & 0.035 & 0.110 & 0.034 \\
\hline resident in Barcelona & 0.305 & 0.460 & 0.326 & 0.469 \\
\hline \# children aged 0-4 & 0.142 & 0.405 & 0.155 & 0.421 \\
\hline \# children aged 5-9 & 0.133 & 0.386 & 0.147 & 0.403 \\
\hline \# children aged 10-15 & 0.177 & 0.440 & 0.194 & 0.460 \\
\hline \# children aged 16-19 & 0.209 & 0.471 & 0.210 & 0.468 \\
\hline number of adults in the household & 2.706 & 1.199 & 2.630 & 1.149 \\
\hline car park in the house building & 0.170 & 0.376 & 0.177 & 0.382 \\
\hline usable housing space (in $\mathrm{m}^{2} / 100$ ) & 84.85 & 35.81 & 86.56 & 37.81 \\
\hline Number of observations & & & 4 & \\
\hline
\end{tabular}


Table A2a: Variables Correlation Matrix by Gender, Males

\begin{tabular}{|c|c|c|c|c|c|c|c|c|c|c|c|c|c|c|c|c|c|c|}
\hline & & 1 & 2 & 3 & 4 & 5 & 6 & 7 & 8 & 9 & 10 & 11 & 12 & 13 & 14 & 15 & 16 & 17 \\
\hline 11 & job-education mismatch* & 1.00 & & & & & & & & & & & & & & & & \\
\hline 2 & employment & -- & 1.00 & & & & & & & & & & & & & & & \\
\hline 3 & cars & 0.06 & 0.11 & 1.00 & & & & & & & & & & & & & & \\
\hline 4 & public transport accessibility & 0.06 & -0.03 & -0.27 & 1.00 & & & & & & & & & & & & & \\
\hline 5 & age & -0.23 & 0.06 & 0.01 & 0.07 & 1.00 & & & & & & & & & & & & \\
\hline 6 & no education & -0.49 & -0.04 & -0.08 & -0.03 & 0.17 & 1.00 & & & & & & & & & & & \\
\hline 7 & primary education & -0.31 & -0.04 & -0.06 & -0.08 & 0.11 & -0.12 & 1.00 & & & & & & & & & & \\
\hline 8 & lower secondary education & -0.15 & -0.02 & -0.01 & -0.08 & -0.07 & -0.17 & -0.31 & 1.00 & & & & & & & & & \\
\hline 9 & upper secondary education & -0.03 & 0.01 & 0.00 & 0.06 & -0.03 & -0.10 & -0.18 & -0.26 & 1.00 & & & & & & & & \\
\hline 10 & vocational education - low grade & 0.27 & 0.01 & 0.03 & -0.02 & -0.10 & -0.08 & -0.14 & -0.20 & -0.11 & 1.00 & & & & & & & \\
\hline 11 & vocational education - high grade & 0.36 & 0.03 & 0.05 & 0.02 & -0.09 & -0.08 & -0.14 & -0.20 & -0.12 & -0.09 & 1.00 & & & & & & \\
\hline 12 & tertiary education & 0.38 & 0.05 & 0.07 & 0.15 & 0.03 & -0.11 & -0.20 & -0.29 & -0.17 & -0.13 & -0.13 & 1.00 & & & & & \\
\hline 13 & field of tertiary education $=$ social sciences & 0.25 & 0.03 & 0.04 & 0.09 & 0.00 & -0.06 & -0.12 & -0.17 & -0.10 & -0.07 & -0.07 & 0.58 & 1.00 & & & & \\
\hline 14 & field of tertiary education $=$ humanities & 0.13 & 0.00 & -0.02 & 0.05 & 0.01 & -0.03 & -0.06 & -0.08 & -0.05 & -0.04 & -0.04 & 0.28 & -0.03 & 1.00 & & & \\
\hline 15 & field of tertiary education $=$ health studies & 0.06 & 0.03 & 0.03 & 0.05 & 0.04 & -0.03 & -0.06 & -0.08 & -0.05 & -0.04 & -0.04 & 0.28 & -0.03 & -0.01 & 1.00 & & \\
\hline 16 & field of tertiary education $=$ hard science & 0.14 & 0.02 & 0.02 & 0.05 & 0.01 & -0.03 & -0.06 & -0.09 & -0.05 & -0.04 & -0.04 & 0.30 & -0.03 & -0.02 & -0.02 & 1.00 & \\
\hline 17 & field of tertiary education $=$ technical studies & 0.18 & 0.03 & 0.05 & 0.07 & 0.02 & -0.06 & -0.11 & -0.16 & -0.09 & -0.07 & -0.07 & 0.55 & -0.06 & -0.03 & -0.03 & -0.03 & 1.00 \\
\hline 18 & born in Spain & 0.02 & 0.06 & 0.20 & -0.06 & 0.09 & -0.13 & 0.00 & 0.05 & -0.03 & 0.04 & 0.03 & 0.00 & 0.00 & -0.02 & 0.01 & 0.00 & 0.00 \\
\hline 19 & born in EU15 countries & 0.04 & -0.01 & -0.03 & 0.02 & -0.01 & -0.02 & -0.03 & -0.04 & 0.01 & 0.00 & 0.01 & 0.08 & 0.04 & 0.04 & 0.01 & 0.02 & 0.04 \\
\hline 20 & born in Africa & -0.09 & -0.04 & -0.09 & -0.04 & -0.06 & 0.18 & 0.03 & -0.03 & -0.02 & -0.03 & -0.04 & -0.05 & -0.02 & -0.01 & -0.01 & -0.02 & -0.03 \\
\hline 21 & born in America & 0.04 & -0.03 & -0.14 & 0.07 & -0.06 & 0.00 & -0.02 & -0.01 & 0.06 & -0.02 & -0.01 & 0.01 & 0.00 & 0.00 & -0.01 & 0.00 & 0.01 \\
\hline 22 & born in other countries & 0.00 & -0.02 & -0.11 & 0.08 & -0.04 & 0.04 & 0.00 & -0.01 & 0.01 & -0.02 & -0.01 & 0.00 & 0.00 & 0.01 & 0.00 & -0.01 & 0.00 \\
\hline 23 & marital status $=$ single & 0.12 & -0.13 & -0.10 & 0.04 & -0.61 & -0.07 & -0.05 & 0.02 & 0.01 & 0.04 & 0.05 & -0.01 & 0.00 & 0.03 & -0.03 & 0.00 & -0.01 \\
\hline 24 & marital status $=$ married & -0.12 & 0.14 & 0.12 & -0.05 & 0.54 & 0.07 & 0.05 & -0.02 & -0.02 & -0.03 & -0.04 & 0.01 & 0.00 & -0.03 & 0.02 & 0.00 & 0.01 \\
\hline 25 & marital status $=$ others & -0.01 & -0.04 & -0.07 & 0.01 & 0.12 & 0.00 & 0.01 & -0.01 & 0.02 & -0.01 & -0.02 & 0.00 & 0.00 & 0.00 & 0.01 & 0.00 & 0.00 \\
\hline 26 & local unemployment rate & -0.07 & -0.12 & -0.17 & 0.10 & -0.05 & 0.07 & 0.10 & 0.07 & -0.06 & 0.00 & -0.04 & -0.15 & -0.09 & -0.04 & -0.06 & -0.05 & -0.08 \\
\hline 27 & resident in Barcelona & 0.08 & -0.02 & -0.22 & 0.77 & 0.07 & -0.05 & -0.09 & -0.09 & 0.08 & -0.02 & 0.02 & 0.18 & 0.11 & 0.06 & 0.06 & 0.06 & 0.08 \\
\hline 28 & \# children aged 0-4 & 0.05 & 0.04 & 0.02 & -0.03 & -0.09 & -0.03 & -0.05 & -0.02 & 0.02 & 0.02 & 0.02 & 0.05 & 0.03 & 0.01 & 0.01 & 0.02 & 0.02 \\
\hline 29 & \# children aged 5-9 & 0.03 & 0.05 & 0.02 & -0.03 & 0.00 & -0.03 & -0.03 & 0.00 & 0.02 & 0.01 & 0.00 & 0.03 & 0.02 & 0.00 & 0.02 & 0.02 & 0.01 \\
\hline 30 & \# children aged 10-15 & -0.03 & 0.03 & 0.04 & -0.05 & 0.07 & -0.01 & 0.03 & 0.03 & 0.00 & -0.02 & -0.03 & -0.02 & -0.01 & -0.02 & 0.02 & 0.00 & -0.02 \\
\hline 31 & \# children aged $16-19$ & -0.06 & -0.02 & 0.06 & -0.04 & 0.00 & 0.00 & 0.05 & 0.06 & -0.03 & -0.02 & -0.04 & -0.05 & -0.03 & -0.03 & 0.00 & -0.02 & -0.03 \\
\hline 32 & number of adults in the household & -0.04 & -0.05 & 0.11 & 0.01 & -0.06 & 0.07 & 0.03 & 0.01 & -0.04 & -0.02 & 0.00 & -0.05 & -0.04 & -0.02 & -0.02 & -0.02 & -0.01 \\
\hline 33 & car park in the house building & 0.04 & 0.03 & 0.18 & -0.23 & 0.03 & -0.04 & -0.04 & -0.03 & 0.02 & 0.00 & 0.02 & 0.07 & 0.04 & 0.01 & 0.03 & 0.02 & 0.04 \\
\hline 34 & usable housing space (in $\mathrm{m}^{2} / 100$ ) & 0.07 & 0.05 & 0.26 & -0.22 & 0.06 & -0.07 & -0.08 & -0.07 & 0.04 & -0.02 & 0.01 & 0.20 & 0.12 & 0.04 & 0.07 & 0.06 & 0.11 \\
\hline
\end{tabular}

Note: * The correlation between job-education mismatch and other variables has been computed for the subsample of employed individuals. 
Table A2a: Variables Correlation Matrix by Gender, Males (continued)

\begin{tabular}{|c|c|c|c|c|c|c|c|c|c|c|c|c|c|c|c|c|c|c|}
\hline & & 18 & 19 & 20 & 21 & 22 & 23 & 24 & 25 & 26 & 27 & 28 & 29 & 30 & 31 & 32 & 33 & 34 \\
\hline 18 & born in Spain & 1.00 & & & & & & & & & & & & & & & & \\
\hline 19 & born in EU15 countries & -0.38 & 1.00 & & & & & & & & & & & & & & & \\
\hline 20 & born in Africa & -0.58 & -0.01 & 1.00 & & & & & & & & & & & & & & \\
\hline 21 & born in America & -0.55 & -0.01 & -0.02 & 1.00 & & & & & & & & & & & & & \\
\hline 22 & born in other countries & -0.41 & 0.00 & -0.01 & -0.01 & 1.00 & & & & & & & & & & & & \\
\hline 23 & marital status $=$ single & -0.03 & 0.01 & 0.02 & 0.02 & 0.01 & 1.00 & & & & & & & & & & & \\
\hline 24 & marital status $=$ married & 0.03 & -0.02 & -0.01 & -0.03 & -0.01 & -0.90 & 1.00 & & & & & & & & & & \\
\hline 25 & marital status $=$ others & 0.01 & 0.01 & -0.02 & 0.01 & -0.01 & -0.19 & -0.27 & 1.00 & & & & & & & & & \\
\hline 26 & local unemployment rate & -0.05 & -0.02 & 0.05 & 0.02 & 0.06 & 0.07 & -0.07 & 0.01 & 1.00 & & & & & & & & \\
\hline 27 & resident in Barcelona & -0.05 & 0.03 & -0.05 & 0.06 & 0.07 & 0.04 & -0.05 & 0.02 & 0.00 & 1.00 & & & & & & & \\
\hline 28 & \# children aged 0-4 & -0.04 & 0.02 & 0.05 & 0.00 & 0.00 & -0.20 & 0.22 & -0.04 & -0.02 & -0.02 & 1.00 & & & & & & \\
\hline 29 & \# children aged 5-9 & 0.01 & 0.00 & 0.00 & 0.00 & -0.02 & -0.21 & 0.22 & -0.04 & -0.02 & -0.02 & 0.12 & 1.00 & & & & & \\
\hline 30 & \# children aged 10-15 & 0.03 & -0.02 & -0.01 & -0.02 & -0.01 & -0.18 & 0.20 & -0.05 & -0.01 & -0.04 & -0.04 & 0.12 & 1.00 & & & & \\
\hline 31 & \# children aged 16-19 & 0.06 & -0.03 & -0.03 & -0.03 & -0.02 & -0.03 & 0.06 & -0.05 & 0.01 & -0.04 & -0.11 & -0.03 & 0.28 & 1.00 & & & \\
\hline 32 & number of adults in the household & -0.18 & -0.04 & 0.13 & 0.10 & 0.13 & 0.20 & -0.14 & -0.12 & 0.04 & -0.01 & -0.17 & -0.16 & -0.17 & -0.08 & 1.00 & & \\
\hline 33 & car park in the house building & 0.06 & 0.01 & -0.05 & -0.03 & -0.04 & -0.06 & 0.06 & -0.01 & -0.21 & -0.12 & 0.03 & 0.04 & 0.03 & 0.03 & -0.02 & 1.00 & \\
\hline 34 & usable housing space (in $\mathrm{m}^{2} / 100$ ) & 0.08 & 0.01 & -0.06 & -0.05 & -0.05 & -0.07 & 0.08 & -0.03 & -0.24 & -0.11 & 0.02 & 0.06 & 0.07 & 0.06 & 0.05 & 0.30 & 1.00 \\
\hline
\end{tabular}


Table A2b: Variables Correlation Matrix by Gender, Females

\begin{tabular}{|c|c|c|c|c|c|c|c|c|c|c|c|c|c|c|c|c|c|c|}
\hline & & 1 & 2 & 3 & 4 & 5 & 6 & 7 & 8 & 9 & 10 & 11 & 12 & 13 & 14 & 15 & 16 & 17 \\
\hline 1 & job-education mismatch* & 1.00 & & & & & & & & & & & & & & & & \\
\hline 2 & employment & -- & 1.00 & & & & & & & & & & & & & & & \\
\hline 3 & cars & 0.04 & 0.05 & 1.00 & & & & & & & & & & & & & & \\
\hline 4 & Public transport accessibility & 0.05 & 0.02 & -0.31 & 1.00 & & & & & & & & & & & & & \\
\hline 5 & age & -0.25 & 0.01 & -0.03 & 0.12 & 1.00 & & & & & & & & & & & & \\
\hline 6 & no education & -0.44 & -0.04 & -0.06 & -0.03 & 0.19 & 1.00 & & & & & & & & & & & \\
\hline 7 & primary education & -0.29 & -0.05 & -0.06 & -0.06 & 0.18 & -0.09 & 1.00 & & & & & & & & & & \\
\hline 8 & lower secondary education & -0.25 & -0.06 & -0.01 & -0.07 & 0.01 & -0.14 & -0.26 & 1.00 & & & & & & & & & \\
\hline 9 & upper secondary education & -0.07 & 0.03 & 0.00 & 0.04 & -0.06 & -0.09 & -0.16 & -0.26 & 1.00 & & & & & & & & \\
\hline 10 & vocational education - low grade & 0.19 & -0.01 & 0.02 & -0.03 & -0.09 & -0.07 & -0.12 & -0.19 & -0.12 & 1.00 & & & & & & & \\
\hline 11 & vocational education - high grade & 0.30 & 0.02 & 0.03 & -0.01 & -0.16 & -0.07 & -0.12 & -0.19 & -0.12 & -0.09 & 1.00 & & & & & & \\
\hline 12 & tertiary education & 0.45 & 0.10 & 0.07 & 0.13 & -0.04 & -0.12 & -0.21 & -0.34 & -0.21 & -0.16 & -0.16 & 1.00 & & & & & \\
\hline 13 & field of tertiary education $=$ social sciences & 0.32 & 0.06 & 0.05 & 0.08 & -0.05 & -0.08 & -0.14 & -0.22 & -0.14 & -0.10 & -0.10 & 0.66 & 1.00 & & & & \\
\hline 14 & field of tertiary education = humanities & 0.18 & 0.03 & 0.00 & 0.07 & 0.01 & -0.04 & -0.07 & -0.12 & -0.07 & -0.05 & -0.05 & 0.35 & -0.06 & 1.00 & & & \\
\hline 15 & field of tertiary education $=$ health studies & 0.10 & 0.06 & 0.05 & 0.05 & 0.02 & -0.05 & -0.09 & -0.14 & -0.09 & -0.06 & -0.06 & 0.41 & -0.08 & -0.04 & 1.00 & & \\
\hline 16 & field of tertiary education $=$ hard science & 0.13 & 0.03 & 0.03 & 0.02 & -0.02 & -0.03 & -0.06 & -0.09 & -0.06 & -0.04 & -0.04 & 0.26 & -0.05 & -0.03 & -0.03 & 1.00 & \\
\hline 17 & field of tertiary education $=$ technical studies & 0.11 & 0.02 & 0.02 & 0.03 & -0.04 & -0.03 & -0.05 & -0.08 & -0.05 & -0.04 & -0.04 & 0.23 & -0.04 & -0.02 & -0.03 & -0.02 & 1.00 \\
\hline 18 & born in Spain & -0.05 & 0.01 & 0.18 & -0.08 & 0.07 & -0.05 & 0.00 & 0.03 & -0.05 & 0.03 & 0.02 & 0.00 & 0.00 & -0.01 & 0.02 & 0.00 & -0.03 \\
\hline 19 & born in EU15 countries & 0.04 & -0.01 & -0.02 & 0.02 & -0.01 & -0.01 & -0.02 & -0.03 & 0.01 & -0.01 & 0.01 & 0.06 & 0.04 & 0.06 & -0.01 & 0.01 & 0.02 \\
\hline 20 & born in Africa & -0.04 & -0.02 & -0.06 & -0.01 & -0.05 & 0.10 & 0.02 & -0.01 & -0.01 & -0.01 & -0.02 & -0.03 & -0.02 & -0.01 & -0.02 & -0.01 & -0.01 \\
\hline 21 & born in America & 0.06 & 0.00 & -0.16 & 0.09 & -0.04 & 0.01 & -0.01 & -0.01 & 0.06 & -0.03 & -0.01 & -0.01 & -0.01 & -0.01 & -0.01 & -0.01 & 0.02 \\
\hline 22 & born in other countries & 0.01 & 0.00 & -0.07 & 0.04 & -0.03 & 0.02 & 0.01 & -0.01 & 0.02 & -0.01 & -0.01 & -0.01 & -0.01 & 0.01 & -0.01 & 0.00 & 0.01 \\
\hline 23 & marital status $=$ single & 0.14 & 0.00 & -0.12 & 0.06 & -0.51 & -0.09 & -0.09 & -0.04 & 0.03 & 0.02 & 0.09 & 0.07 & 0.05 & 0.02 & 0.01 & 0.02 & 0.04 \\
\hline 24 & marital status $=$ married & -0.09 & -0.01 & 0.22 & -0.08 & 0.34 & 0.06 & 0.05 & 0.03 & -0.03 & -0.01 & -0.06 & -0.03 & -0.02 & -0.02 & 0.00 & -0.01 & -0.02 \\
\hline 25 & marital status $=$ others & -0.08 & 0.02 & -0.17 & 0.03 & 0.23 & 0.04 & 0.06 & 0.02 & 0.00 & -0.01 & -0.05 & -0.06 & -0.04 & -0.01 & -0.01 & -0.02 & -0.02 \\
\hline 26 & local unemployment rate & -0.06 & -0.10 & -0.16 & 0.10 & -0.06 & 0.07 & 0.09 & 0.06 & -0.04 & 0.01 & -0.02 & -0.15 & -0.09 & -0.04 & -0.07 & -0.04 & -0.03 \\
\hline 27 & resident in Barcelona & 0.06 & 0.02 & -0.26 & 0.79 & 0.13 & -0.03 & -0.07 & -0.08 & 0.05 & -0.03 & -0.01 & 0.15 & 0.10 & 0.08 & 0.06 & 0.03 & 0.03 \\
\hline 28 & \# children aged 0-4 & 0.07 & -0.04 & 0.07 & -0.04 & -0.14 & -0.05 & -0.07 & -0.03 & 0.02 & 0.02 & 0.03 & 0.07 & 0.04 & 0.03 & 0.02 & 0.03 & 0.02 \\
\hline 29 & \# children aged 5-9 & 0.02 & -0.02 & 0.05 & -0.04 & -0.02 & -0.03 & -0.03 & 0.00 & 0.02 & 0.02 & -0.01 & 0.02 & 0.01 & 0.01 & 0.02 & 0.01 & -0.01 \\
\hline 30 & \# children aged 10-15 & -0.06 & -0.01 & 0.03 & -0.05 & 0.07 & 0.00 & 0.03 & 0.05 & 0.00 & 0.01 & -0.05 & -0.05 & -0.04 & -0.02 & 0.00 & -0.01 & -0.02 \\
\hline 31 & \# children aged $16-19$ & -0.10 & -0.02 & 0.05 & -0.04 & 0.03 & 0.02 & 0.07 & 0.08 & -0.03 & -0.02 & -0.06 & -0.08 & -0.07 & -0.03 & -0.01 & -0.03 & -0.02 \\
\hline 32 & number of adults in the household & 0.00 & -0.02 & 0.13 & 0.01 & -0.08 & 0.04 & 0.03 & 0.01 & -0.03 & -0.01 & 0.02 & -0.04 & -0.02 & -0.03 & -0.02 & 0.00 & 0.01 \\
\hline 33 & car park in the house building & 0.02 & 0.02 & 0.19 & -0.24 & 0.02 & -0.04 & -0.04 & -0.02 & 0.02 & -0.01 & 0.01 & 0.06 & 0.04 & 0.01 & 0.04 & 0.03 & 0.01 \\
\hline 34 & usable housing space (in $\mathrm{m}^{2} / 100$ ) & 0.04 & 0.04 & 0.28 & -0.20 & 0.07 & -0.06 & -0.07 & -0.06 & 0.02 & -0.02 & -0.02 & 0.16 & 0.10 & 0.06 & 0.08 & 0.04 & 0.03 \\
\hline
\end{tabular}

Note: * The correlation between job-education mismatch and other variables has been computed for the subsample of employed individuals 
Table A2b: Variables Correlation Matrix by Gender, Females (continued)

\begin{tabular}{|c|c|c|c|c|c|c|c|c|c|c|c|c|c|c|c|c|c|c|}
\hline & & 18 & 19 & 20 & 21 & 22 & 23 & 24 & 25 & 26 & 27 & 28 & 29 & 30 & 31 & 32 & 33 & 34 \\
\hline 18 & born in Spain & 1.00 & & & & & & & & & & & & & & & & \\
\hline 19 & born in EU15 countries & -0.39 & 1.00 & & & & & & & & & & & & & & & \\
\hline 20 & born in Africa & -0.39 & -0.01 & 1.00 & & & & & & & & & & & & & & \\
\hline 21 & born in America & -0.73 & -0.01 & -0.01 & 1.00 & & & & & & & & & & & & & \\
\hline 22 & born in other countries & -0.36 & 0.02 & -0.01 & -0.01 & 1.00 & & & & & & & & & & & & \\
\hline 23 & marital status $=$ single & -0.05 & 0.03 & 0.01 & 0.04 & 0.00 & 1.00 & & & & & & & & & & & \\
\hline 24 & marital status $=$ married & 0.05 & -0.02 & -0.01 & -0.05 & 0.00 & -0.81 & 1.00 & & & & & & & & & & \\
\hline 25 & marital status $=$ others & 0.00 & 0.00 & 0.00 & 0.01 & 0.00 & -0.26 & -0.37 & 1.00 & & & & & & & & & \\
\hline 26 & local unemployment rate & -0.04 & -0.02 & 0.04 & 0.03 & 0.03 & 0.07 & -0.07 & 0.01 & 1.00 & & & & & & & & \\
\hline 27 & resident in Barcelona & -0.07 & 0.03 & -0.02 & 0.07 & 0.04 & 0.04 & -0.06 & 0.03 & 0.01 & 1.00 & & & & & & & \\
\hline 28 & \# children aged 0-4 & 0.00 & 0.00 & 0.03 & -0.02 & 0.00 & -0.19 & 0.22 & -0.06 & -0.03 & -0.03 & 1.00 & & & & & & \\
\hline 29 & \# children aged 5-9 & 0.02 & 0.00 & 0.00 & -0.01 & -0.02 & -0.20 & 0.20 & -0.01 & -0.03 & -0.02 & 0.10 & 1.00 & & & & & \\
\hline 30 & \# children aged 10-15 & 0.02 & -0.01 & 0.01 & -0.03 & -0.01 & -0.18 & 0.15 & 0.03 & 0.00 & -0.04 & -0.07 & 0.09 & 1.00 & & & & \\
\hline 31 & \# children aged 16-19 & 0.04 & -0.02 & 0.01 & -0.04 & -0.01 & -0.06 & 0.05 & 0.02 & 0.02 & -0.05 & -0.13 & -0.04 & 0.27 & 1.00 & & & \\
\hline 32 & number of adults in the household & -0.15 & -0.02 & 0.07 & 0.13 & 0.08 & 0.23 & -0.12 & -0.16 & 0.03 & -0.01 & -0.16 & -0.16 & -0.18 & -0.07 & 1.00 & & \\
\hline 33 & car park in the house building & 0.05 & 0.01 & -0.03 & -0.04 & -0.02 & -0.07 & 0.08 & -0.03 & -0.21 & -0.14 & 0.03 & 0.04 & 0.03 & 0.02 & -0.01 & 1.00 & \\
\hline 34 & usable housing space (in $\mathrm{m}^{2} / 100$ ) & 0.06 & 0.02 & -0.04 & -0.05 & -0.03 & -0.07 & 0.10 & -0.05 & -0.24 & -0.11 & 0.03 & 0.06 & 0.07 & 0.07 & 0.08 & 0.30 & 1.00 \\
\hline
\end{tabular}


Table A3: Average Elasticity of Public Transport Accessibility and Car Ownership (Independent Equations)

\begin{tabular}{|c|c|c|c|c|c|}
\hline \multicolumn{6}{|c|}{ OUTCOME } \\
\hline & $\begin{array}{l}\% \Delta[\text { [years of } \\
\text { overeducation] }\end{array}$ & $\% \Delta \operatorname{Pr}[$ employed] & $\% \Delta \operatorname{Pr}[$ cars $=0]$ & $\% \Delta \operatorname{Pr}[$ cars $=1]$ & $\% \Delta \operatorname{Pr}[$ cars $\geq 2]$ \\
\hline \multicolumn{6}{|l|}{ MALES } \\
\hline$\% \Delta($ public transport accessibility) & -0.057 & 0.002 & 0.908 & 0.035 & -0.838 \\
\hline$\Delta 0$ to 1 car & -0.026 & 0.067 & & & \\
\hline$\Delta 1$ to 2 cars & -0.018 & 0.016 & & & \\
\hline \multicolumn{6}{|l|}{ FEMALES } \\
\hline$\% \Delta($ public transport accessibility) & -0.047 & 0.059 & 0.978 & 0.000 & -0.977 \\
\hline$\Delta 0$ to 1 car & -0.047 & 0.024 & & & \\
\hline$\Delta 1$ to 2 cars & -0.027 & 0.079 & & & \\
\hline
\end{tabular}

Note: the marginal effect of public transport accessibility is computed as the changes in predicted outcomes after a 10\% change in public transport accessibility (elasticity). The marginal effect of car ownership is the changes in predicted outcomes after switching from 0 to 1 car and from 1 to 2 cars respectively. The elasticity of the years of overeducation has been computed considering individuals to be overeducated when they have more years of schooling than the average in their respective occupation plus one standard deviation point (i.e. mismatch greater than the standard deviation of years of schooling in each occupation). Numbers in bold type indicate that the corresponding coefficient is significant at a 5\% significance level.

Table A4: Sensitivity Analysis

\begin{tabular}{|c|c|c|}
\hline OUTCOME & \multicolumn{2}{|c|}{$\% \Delta[y e a r s$ of overeducation] } \\
\hline \multicolumn{3}{|l|}{ baseline sample } \\
\hline & MALES $(\mathrm{n}=44077)$ & FEMALES $(\mathrm{n}=48961)$ \\
\hline$\% \Delta$ (public transport accessibility) & -0.086 & -0.081 \\
\hline$\triangle 0$ to $1 \mathrm{car}$ & -0.076 & -0.141 \\
\hline$\Delta 1$ to 2 cars & -0.084 & -0.120 \\
\hline \multicolumn{3}{|c|}{ only individuals residing in the same place for more than 10 years } \\
\hline & MALES $(n=22765)$ & FEMALES $(\mathrm{n}=25871)$ \\
\hline$\% \Delta$ (public transport accessibility) & -0.097 & -0.096 \\
\hline$\Delta 0$ to 1 car & -0.059 & -0.120 \\
\hline$\Delta 1$ to 2 cars & -0.068 & -0.093 \\
\hline \multicolumn{3}{|c|}{ only individuals residing with their parents } \\
\hline & MALES $(n=11116)$ & FEMALES $(\mathrm{n}=7416)$ \\
\hline$\% \Delta$ (public transport accessibility) & -0.083 & -0.057 \\
\hline$\Delta 0$ to $1 \mathrm{car}$ & -0.060 & -0.038 \\
\hline$\Delta 1$ to 2 cars & -0.053 & -0.035 \\
\hline \multicolumn{3}{|l|}{ only head of household } \\
\hline & MALES $(n=23545)$ & FEMALES $(\mathrm{n}=15007)$ \\
\hline
\end{tabular}




\begin{tabular}{lll}
\hline$\% \Delta$ (public transport accessibility) & $\mathbf{- 0 . 1 1 5}$ & -0.027 \\
$\Delta 0$ to 1 car & $\mathbf{- 0 . 1 3 9}$ & $\mathbf{- 0 . 0 7 4}$ \\
$\Delta 1$ to 2 cars & $\mathbf{- 0 . 1 5 7}$ & $\mathbf{- 0 . 0 7 5}$
\end{tabular}

Note: the marginal effect of public transport accessibility is computed as the changes in predicted outcomes after a 10\% change in public transport accessibility (elasticity). The marginal effect of car ownership is the changes in predicted outcomes after switching from 0 to 1 car and from 1 to 2 cars respectively. The elasticity of the years of overeducation has been computed considering individuals to be overeducated when they have more years of schooling than the average in their respective occupation plus one standard deviation point (i.e. mismatch greater than the standard deviation of years of schooling in each occupation). Numbers in bold type indicate that the corresponding coefficient is significant at a 5\% significance level. 
Table A5: Descriptive Statistics for Selected Subsamples for Sensitivity Analysis

\begin{tabular}{|c|c|c|c|c|c|c|c|c|c|c|c|c|}
\hline & \multicolumn{4}{|c|}{ (a) } & \multicolumn{4}{|c|}{ (b) } & \multicolumn{4}{|c|}{ (c) } \\
\hline & \multicolumn{2}{|c|}{ MALES } & \multicolumn{2}{|c|}{ "FEMALES } & \multicolumn{2}{|c|}{$\begin{array}{l}\text { MALES } \\
\end{array}$} & \multicolumn{2}{|c|}{ FEMALES } & \multicolumn{2}{|c|}{ MALES } & \multicolumn{2}{|c|}{ FEMALES } \\
\hline & mean & s.d. & mean & s.d. & mean & s.d. & mean & s.d. & mean & s.d. & mean & s.d. \\
\hline public transport accessibility (pta) & 3.312 & 1.076 & 3.365 & 1.086 & 3.182 & 1.079 & 3.252 & 1.096 & 3.166 & 1.123 & 3.310 & 1.166 \\
\hline cars $=0$ & 0.174 & 0.379 & 0.200 & 0.400 & 0.201 & 0.401 & 0.220 & 0.414 & 0.162 & 0.368 & 0.269 & 0.444 \\
\hline cars $=1$ & 0.528 & 0.499 & 0.533 & 0.499 & 0.438 & 0.496 & 0.465 & 0.499 & 0.584 & 0.493 & 0.515 & 0.500 \\
\hline cars $\geq 2$ & 0.298 & 0.457 & 0.267 & 0.443 & 0.361 & 0.480 & 0.315 & 0.465 & 0.254 & 0.435 & 0.216 & 0.411 \\
\hline employed & 0.878 & 0.328 & 0.534 & 0.499 & 0.827 & 0.379 & 0.806 & 0.396 & 0.937 & 0.244 & 0.817 & 0.387 \\
\hline job-education mismatch (years) & -0.305 & 3.090 & -0.219 & 3.021 & 0.551 & 2.966 & 0.717 & 2.968 & -0.162 & 3.158 & 0.342 & 3.099 \\
\hline overeducation (schooling > occupation-average + s.d.) & 0.145 & 0.353 & 0.145 & 0.352 & 0.207 & 0.405 & 0.221 & 0.415 & 0.160 & 0.367 & 0.195 & 0.396 \\
\hline age & 40.34 & 13.20 & 43.81 & 12.46 & 26.72 & 7.18 & 26.73 & 7.43 & 43.73 & 10.43 & 41.42 & 10.61 \\
\hline no education & 0.071 & 0.256 & 0.112 & 0.316 & 0.027 & 0.161 & 0.019 & 0.135 & 0.073 & 0.261 & 0.065 & 0.247 \\
\hline primary education & 0.203 & 0.402 & 0.236 & 0.425 & 0.152 & 0.359 & 0.093 & 0.290 & 0.184 & 0.387 & 0.148 & 0.355 \\
\hline lower secondary education & 0.321 & 0.467 & 0.309 & 0.462 & 0.350 & 0.477 & 0.284 & 0.451 & 0.289 & 0.453 & 0.247 & 0.432 \\
\hline upper secondary education & 0.115 & 0.319 & 0.103 & 0.304 & 0.126 & 0.332 & 0.145 & 0.353 & 0.119 & 0.324 & 0.134 & 0.340 \\
\hline vocational education - low grade & 0.074 & 0.262 & 0.056 & 0.230 & 0.102 & 0.303 & 0.093 & 0.291 & 0.074 & 0.263 & 0.083 & 0.275 \\
\hline vocational education - high grade & 0.077 & 0.266 & 0.050 & 0.217 & 0.108 & 0.311 & 0.129 & 0.335 & 0.078 & 0.269 & 0.074 & 0.262 \\
\hline tertiary education & 0.139 & 0.346 & 0.134 & 0.341 & 0.135 & 0.342 & 0.237 & 0.425 & 0.182 & 0.386 & 0.249 & 0.432 \\
\hline field of tertiary education $=$ social sciences & 0.050 & 0.217 & 0.066 & 0.248 & 0.052 & 0.223 & 0.125 & 0.330 & 0.066 & 0.249 & 0.121 & 0.326 \\
\hline field of tertiary education $=$ humanities & 0.013 & 0.113 & 0.020 & 0.140 & 0.013 & 0.113 & 0.027 & 0.163 & 0.016 & 0.127 & 0.040 & 0.196 \\
\hline field of tertiary education $=$ health studies & 0.013 & 0.114 & 0.029 & 0.167 & 0.008 & 0.091 & 0.043 & 0.203 & 0.019 & 0.136 & 0.054 & 0.225 \\
\hline field of tertiary education $=$ hard science & 0.014 & 0.118 & 0.010 & 0.102 & 0.013 & 0.113 & 0.021 & 0.144 & 0.020 & 0.139 & 0.020 & 0.140 \\
\hline field of tertiary education $=$ technical studies & 0.049 & 0.216 & 0.010 & 0.097 & 0.048 & 0.214 & 0.021 & 0.143 & 0.061 & 0.239 & 0.013 & 0.115 \\
\hline born in Spain & 0.990 & 0.098 & 0.989 & 0.106 & 0.989 & 0.105 & 0.988 & 0.111 & 0.952 & 0.213 & 0.952 & 0.213 \\
\hline born in EU15 countries & 0.003 & 0.051 & 0.003 & 0.059 & 0.002 & 0.040 & 0.002 & 0.040 & 0.010 & 0.100 & 0.010 & 0.101 \\
\hline born in Africa & 0.003 & 0.052 & 0.002 & 0.040 & 0.004 & 0.061 & 0.003 & 0.059 & 0.017 & 0.130 & 0.008 & 0.088 \\
\hline born in America & 0.003 & 0.054 & 0.005 & 0.070 & 0.004 & 0.063 & 0.006 & 0.077 & 0.013 & 0.111 & 0.024 & 0.154 \\
\hline born in other countries & 0.001 & 0.039 & 0.001 & 0.038 & 0.002 & 0.041 & 0.001 & 0.038 & 0.008 & 0.088 & 0.005 & 0.073 \\
\hline marital status $=$ single & 0.443 & 0.497 & 0.276 & 0.447 & 1.000 & 0.000 & 1.000 & 0.000 & 0.158 & 0.364 & 0.210 & 0.407 \\
\hline marital status $=$ married & 0.512 & 0.500 & 0.640 & 0.480 & 0.000 & 0.000 & 0.000 & 0.000 & 0.775 & 0.418 & 0.565 & 0.496 \\
\hline marital status $=$ others & 0.045 & 0.207 & 0.084 & 0.277 & 0.000 & 0.000 & 0.000 & 0.000 & 0.068 & 0.251 & 0.225 & 0.418 \\
\hline Number of observations & \multicolumn{2}{|c|}{22,765} & \multicolumn{2}{|c|}{25,871} & \multicolumn{2}{|c|}{11,116} & \multicolumn{2}{|c|}{7,416} & \multicolumn{2}{|c|}{$23,54 \overline{\overline{4}}$} & \multicolumn{2}{|c|}{15,007} \\
\hline
\end{tabular}

Note: (a) only individuals residing in the same place for more than 10 years; $(b)$ only individuals residing with their parents; (c) only head of the household. 
Table A5: Descriptive Statistics for Selected Subsamples for Sensitivity Analysis (continued)

\begin{tabular}{|c|c|c|c|c|c|c|c|c|c|c|c|c|}
\hline & \multicolumn{4}{|c|}{ (a) } & \multicolumn{4}{|c|}{ (b) } & \multicolumn{4}{|c|}{ (c) } \\
\hline & \multicolumn{2}{|c|}{ MALES } & \multicolumn{2}{|c|}{ FEMALES } & \multicolumn{2}{|c|}{ MALES } & \multicolumn{2}{|c|}{ FEMALES } & \multicolumn{2}{|c|}{ MALES } & \multicolumn{2}{|c|}{ FEMALES } \\
\hline & mean & s.d. & mean & s.d. & mean & s.d. & mean & s.d. & mean & s.d. & mean & s.d. \\
\hline local unemployment rate & 0.114 & 0.035 & 0.113 & 0.034 & 0.114 & 0.037 & 0.113 & 0.036 & 0.111 & 0.034 & 0.109 & 0.034 \\
\hline resident in Barcelona & 0.343 & 0.475 & 0.369 & 0.482 & 0.294 & 0.455 & 0.324 & 0.468 & 0.300 & 0.458 & 0.376 & 0.484 \\
\hline \# children aged 0-4 & 0.037 & 0.207 & 0.042 & 0.217 & 0.009 & 0.106 & 0.009 & 0.109 & 0.182 & 0.452 & 0.175 & 0.437 \\
\hline \# children aged 5-9 & 0.091 & 0.322 & 0.097 & 0.330 & 0.026 & 0.177 & 0.029 & 0.194 & 0.169 & 0.428 & 0.156 & 0.412 \\
\hline \# children aged 10-15 & 0.188 & 0.442 & 0.197 & 0.455 & 0.102 & 0.329 & 0.099 & 0.334 & 0.212 & 0.477 & 0.201 & 0.473 \\
\hline \# children aged 16-19 & 0.261 & 0.508 & 0.254 & 0.499 & 0.281 & 0.543 & 0.269 & 0.530 & 0.200 & 0.457 & 0.184 & 0.441 \\
\hline number of adults in the household & 2.961 & 1.101 & 2.861 & 1.082 & 3.401 & 1.035 & 3.458 & 1.016 & 2.337 & 0.984 & 2.100 & 0.959 \\
\hline car park in the house building & 0.130 & 0.336 & 0.136 & 0.343 & 0.155 & 0.362 & 0.155 & 0.362 & 0.177 & 0.382 & 0.169 & 0.375 \\
\hline usable housing space (in $\mathrm{m}^{2} / 100$ ) & 82.65 & 32.93 & 83.94 & 35.07 & 85.14 & 37.13 & 87.04 & 38.82 & 84.72 & 35.06 & 83.81 & 34.90 \\
\hline Number of observations & \multicolumn{2}{|c|}{22,765} & \multicolumn{2}{|c|}{25,871} & \multicolumn{2}{|c|}{11,116} & \multicolumn{2}{|c|}{7,416} & \multicolumn{2}{|c|}{23,545} & \multicolumn{2}{|c|}{15,007} \\
\hline
\end{tabular}

Note: (a) only individuals residing in the same place for more than 10 years; $(b)$ only individuals residing with their parents; (c) only head of the household. 
Table A6: Accounting for Private Transport Accessibility (Selected Estimates)

\begin{tabular}{|lcccc|}
\hline & \multicolumn{3}{c}{ MALES } & \multicolumn{3}{c|}{ FEMALES } \\
\hline \hline mismatch & \multicolumn{5}{c|}{} \\
\hline \hline public transport accessibility (pta) & $-0.128^{\mathrm{a}}$ & $-0.147^{\mathrm{a}}$ & $-0.115^{\mathrm{a}}$ & $-0.136^{\mathrm{a}}$ \\
& $(-6.966)$ & $(-6.911)$ & $(-4.413)$ & $(-4.677)$ \\
cars $=0$ & & reference category & \\
cars $=1$ & $-0.411^{\mathrm{a}}$ & $-0.411^{\mathrm{a}}$ & $-0.793^{\mathrm{a}}$ & $-0.790^{\mathrm{a}}$ \\
& $(-4.351)$ & $(-4.351)$ & $(-5.729)$ & $(-5.713)$ \\
cars $\geq 2$ & $-0.829^{\mathrm{a}}$ & $-0.829^{\mathrm{a}}$ & $-1.374^{\mathrm{a}}$ & $-1.367^{\mathrm{a}}$ \\
& $(-4.673)$ & $(-4.673)$ & $(-5.168)$ & $(-5.150)$ \\
private transport accessibility & & $0.015^{\mathrm{c}}$ & & 0.016 \\
& & $(1.806)$ & & $(1.570)$ \\
\hline \hline employment & \multicolumn{5}{c}{} \\
\hline public transport accessibility (pta) & 0.011 & -0.011 & $0.052^{\mathrm{a}}$ & $0.065^{\mathrm{a}}$ \\
& $(0.624)$ & $(-0.552)$ & $(4.066)$ & $(4.450)$ \\
cars $=0$ & & reference & category & \\
cars $=1$ & $0.346^{\mathrm{a}}$ & $0.356^{\mathrm{a}}$ & $0.218^{\mathrm{a}}$ & $0.212^{\mathrm{a}}$ \\
& $(3.316)$ & $(3.380)$ & $(3.164)$ & $(3.062)$ \\
cars $\geq 2$ & $0.497^{\mathrm{b}}$ & $0.517^{\mathrm{b}}$ & $0.520^{\mathrm{a}}$ & $0.507^{\mathrm{a}}$ \\
& $(2.436)$ & $(2.508)$ & $(3.909)$ & $(3.796)$ \\
private transport accessibility & & $0.017^{\mathrm{b}}$ & & $-0.010^{\mathrm{b}}$ \\
& & $(2.529)$ & & $(-2.033)$ \\
\hline \hline Number of observations & 44,077 & 44,077 & 48,961 & 48,961 \\
\hline
\end{tabular}

Note: ${ }^{a}$ significant at $1 \%$ level, ${ }^{b}$ significant at $5 \%$ level, ${ }^{c}$ significant at $10 \%$ level; t-Statistics in parenthesis, standard errors clustered at the census tract level. Private transport accessibility has been computed in the same fashion than public transport job accessibility (see section 3.2) but using private transport time. All the equations contain the same set of covariates than in the baseline estimations of table 2. 